\title{
Dynamic Inputs and Resource (Mis)Allocation
}

\section{John Asker}

University of California, Los Angeles, and National Bureau of Economic Research

\section{Allan Collard-Wexler}

Duke University and National Bureau of Economic Research

\section{Jan De Loecker}

Princeton University and National Bureau of Economic Research

\begin{abstract}
We investigate the role of dynamic production inputs and their associated adjustment costs in shaping the dispersion of static measures of capital misallocation within industries (and countries). Across nine data sets spanning 40 countries, we find that industries exhibiting greater time-series volatility of productivity have greater cross-sectional dispersion of the marginal revenue product of capital. We use a standard investment model with adjustment costs to show that variation in the volatility of productivity across these industries and economies can explain a large share (80-90 percent) of the cross-industry (and cross-country) variation in the dispersion of the marginal revenue product of capital.
\end{abstract}

\footnotetext{
An earlier version of this paper was titled "Productivity Volatility and the Misallocation of Resources in Developing Economies." We would like to thank the editor and four anonymous referees for excellent comments and suggestions. Furthermore, we thank Dave Backus, Nick Bloom, Gian Luca Clementi, John Fernald, Alessandro Gavazza, Chang-Tai Hsieh, Panle Jia Barwick, Pete Klenow, Marc Melitz, Richard Rogerson, Daniel Xu, Jonathan Fisher, Larry White, and numerous seminar participants for their comments. This paper uses restricted data that were analyzed at the US Census Bureau Research Data Center in New York City. Any opinions and conclusions expressed herein are those of the authors and do not necessarily represent the views of the US Census Bureau. All results have been reviewed to ensure that no confidential information is disclosed. Financial assistance from the Center for Global Economy and Business at New York University Stern is greatly appreciated. The usual caveat applies.
}

[Journal of Political Economy, 2014, vol. 122, no. 5]

(c) 2014 by The University of Chicago. All rights reserved. 0022-3808/2014/12205-0005\$10.00 


\section{Introduction}

It is well documented that firms differ in productivity within even narrowly defined industries. ${ }^{1}$ Moreover, across countries, the extent of this dispersion varies considerably, particularly when comparing countries at different stages of economic development. Dispersion is also observed in the marginal revenue products of inputs, particularly capital. Viewed through a standard static model of production and demand, variation in marginal products across firms suggests the existence of frictions that prevent the efficient allocation of resources in an industry, or an economy at large.

Mirroring this observation, quantitative studies find that reallocation of capital to more productive uses has important implications for aggregate productivity and welfare, within industries, countries, and over time (see, e.g., Olley and Pakes 1996; Hsieh and Klenow 2009; Bartelsman et al. 2013; Collard-Wexler and De Loecker, forthcoming). Spurred by this set of facts, a number of recent papers have tried to identify specific mechanisms to explain why productivity differences are not eliminated by market-based resource reallocation. ${ }^{2}$

This paper investigates the role of dynamically chosen inputs, such as capital, in shaping the dispersion of the marginal product of inputs. Specifically, we consider a variant of a standard dynamic investment model in which firms $(a)$ face costs when adjusting one factor of production (capital), (b) can acquire all inputs in a frictionless spot market, and $(c)$ get a firm-specific productivity shock (measured using revenue total factor productivity, or TFPR) in each period generated by an $\mathrm{AR}(1)$ process. ${ }^{3}$ Thus, a capital stock determined in some previous period may no longer appear to be optimal after a productivity shock hits. As a result, dispersion in the marginal revenue product of capital arises naturally. ${ }^{4}$ A literal implication is that resource allocation, while appearing inefficient in a static setting, may well be efficient in a dynamic sense. ${ }^{5}$

${ }^{1}$ We define our measure of productivity, TFPR, below and discuss its measurement in detail. For recent work, see Bartelsman and Doms (2000), Syverson (2011), Bartelsman, Haltiwanger, and Scarpetta (2013), and references therein.

${ }^{2}$ See Restuccia and Rogerson (2008), Collard-Wexler (2009), Hsieh and Klenow (2009), Bollard, Klenow, and Sharma (2012), Moll (2012), Peters (2012), and Midrigan and Xu (2014) for recent work.

${ }_{3}^{3}$ Throughout the paper, in discussing our own work, we consider productivity to be TFPR and use the terms interchangeably.

${ }^{4}$ We focus on the marginal revenue product of capital as this seems to be the input that is most prone to adjustment costs. This is consistent with data, as we discuss in Sec. IV.C: we observe more dispersion in the marginal product of capital relative to that of other inputs.

${ }^{5}$ The validity of this literal interpretation rests on the relationship between the TFPR process and policy. Whether this process in amenable to policy adjustment is a question we turn to in the conclusion. 
We then evaluate the empirical value of this model, employing two types of data: The first is country-specific data, which we will refer to as tier 1 data, on establishment/firm production in manufacturing in each of the United States, Chile, France, India, Mexico, Romania, Slovenia, and Spain (all of which have been widely used in the development and productivity literatures). The second data, which we call tier 2, are from the World Bank Enterprise Survey (WBES); they allow us to exploit production data on firms in 33 countries. ${ }^{6}$ Each type of data has different strengths: the country-specific data sets have many more observations and tighter data collection protocols, while the WBES data allow us to access a broader set of countries.

The basic reduced-form pattern implied by the model - that as the volatility of TFPR increases, so does the dispersion of marginal product of capital-is strongly supported by data. It is supported both across industries within a country (using the tier 1 data) and across countries (using the tier 2 data).

After documenting this basic reduced-form pattern, we take a more structural approach to see how well the model captures cross-industry variation in dispersion. For this exercise, we first estimate capital adjustment costs. These adjustment cost estimates, along with an (industry-country specific) AR(1) shock process, are used to generate model predictions (i.e., we hold all other parameters constant). We then confront the model predictions with the data.

We make three specific contributions in this paper: First, we show that the model of dynamic inputs can quantitatively replicate dispersion of the marginal revenue product of capital that is found in the data. This indicates that the model of dynamically chosen inputs provides a natural benchmark for the dispersion of marginal revenue products in an undistorted economy. Indeed the literature on misallocation acknowledges that dispersion of marginal revenue products alone is not evidence of misallocation and that adjustment costs may play an important role (see, e.g., Hsieh and Klenow 2009).

Second, we find meaningful differences in the size of TFPR shocks across industries within countries, as well as across countries, of the same relative magnitude as differences in the cross-sectional dispersion of the marginal revenue product of capital. Moreover, industries (countries) with the greatest volatility of TFPR also have the greatest dispersion of the marginal revenue product of capital. These reduced-form results are robust to a wide range of measurement and model specification concerns, such as alternative specifications of the TFPR process and alternative

\footnotetext{
${ }^{6}$ The WBES data cover firms in the manufacturing, construction, services, transport, storage, and communications sectors.
} 
measures of volatility; these results hold both across industries within a country and across countries.

Third, we show that a structural implementation of this model can capture, both qualitatively and quantitatively, much of the cross-industry (country) variation in the dispersion of marginal revenue products of capital. The model performs strongly: when confronted with industrycountry data on dispersion in the marginal revenue product of capital, it generates a measure of fit equivalent to an uncentered $R^{2}$ of around $.8-.9$, depending on the specification. Our results indicate that, perhaps surprisingly, the exact level of adjustment costs does not change this measure of fit greatly: whether we rely on the US estimated adjustment costs or a country-specific one, the measure of fit is about the same. The absence of adjustment costs, with all other parts of the model held fixed, leads to a drop in our measure of fit, which suggests that adjustment cost and volatility play an important role in shaping differences in the dispersion of marginal revenue product of capital (across industries and countries) and, as a consequence, are crucial to understanding income differences across countries.

Taken as a whole, these results highlight the importance of dynamic inputs in explaining, in both levels and differences, the dispersion of the marginal product of capital. Furthermore, our analysis suggests that producer-level volatility may be an important factor in explaining aggregate welfare. The productivity process we employ is a reduced form for a range of time-varying shocks to production, including (but not limited to) demand shocks, natural disasters, infrastructure shocks, variation in the incidence of corruption or nepotism, changes in markups due to demand shocks or market structure changes, and changes to informational barriers. This paper suggests a channel through which these micro effects can have aggregate implications. ${ }^{7}$

The remainder of the paper is organized as follows: In Section II, we present our dynamic model of investment. Section III presents the data and discusses the measurement of productivity across several countries. We turn to reduced-form empirical evidence and subject it to a variety of robustness checks in Section IV. Section V confronts the predictions of the dynamic investment model with the data using a structural approach. In Section VI, we consider cross-country variation using the WBES data. Finally, we conclude the paper with a discussion of our findings in Section VII.

\footnotetext{
${ }^{7}$ For micro-based studies that consider the effect of each, see Collard-Wexler (2013) on demand shocks; De Mel, McKenzie, and Woodruff (2012) on natural disasters; Fisher-Vanden, Mansur, and Wang (2012) on infrastructure; Fisman and Svensson (2007) on corruption; De Loecker et al. (2012) on markups; and Bloom et al. (2013) on information barriers.
} 


\section{Theoretical Framework}

In this section, we posit a simple model that allows us to consider how the time-series process of TFPR should affect the cross-sectional dispersion of the (static) marginal revenue product of capital and other variables. Central to the model is the role of capital adjustment costs, and a oneperiod time to build, in making optimal capital investment decisions. These adjustment frictions create links between the time-series process generating firm-level TFPR shocks and firm-level heterogeneity in the adjustment of capital stocks.

\section{A. Modeling Preliminaries}

We begin by providing an explicit model of TFPR in the context of a profit-maximizing firm (since we assume that establishments operate as autonomous units, firms and establishments, for our purposes, are synonymous). A firm $i$, in time $t$, produces output $Q_{i t}$ using the following (industry-specific) constant-returns technology:

$$
Q_{i t}=A_{i t} K_{i t}^{\alpha_{K}} L_{i t}^{\alpha_{L}} M_{i t}^{\alpha_{M}},
$$

where $K_{i t}$ is the capital input, $L_{i t}$ is the labor input, $M_{i t}$ is materials, and we assume constant returns to scale in production so $\alpha_{M}+\alpha_{L}+\alpha_{K}=1$. The demand curve for the firm's product has a constant elasticity:

$$
Q_{i t}=B_{i t} P_{i t}^{-\epsilon} .
$$

Combining these two equations, we obtain an expression for the salesgenerating production function:

$$
S_{i t}=\Omega_{i t} K_{i t}^{\beta_{K}} L_{i t}^{\beta_{L}} M_{i t}^{\beta_{M}},
$$

where $\Omega_{i t}=A_{i t}^{1-(1 / \epsilon)} B_{i t}^{1 / \epsilon} b$ and $\beta_{X}=\alpha_{X}[1-(1 / \epsilon)]$ for $X \in\{K, L, M\}$. For the purposes of this paper, productivity or TFPR is defined as $\omega_{i t} \equiv \ln \left(\Omega_{i t}\right)^{8}{ }^{8}$

The production function and sales-generating function are industry specific; throughout the paper, the coefficients $\beta$ and $\alpha$ are kept country and industry specific unless noted otherwise. For ease of measurement, we set $\epsilon$ to be constant for all firms, industries, and countries.

A fact that we will use repeatedly is that, in a static model with no frictions, profit maximization implies that the marginal revenue product of an input should be equal to its unit input cost. For capital, this static marginal revenue product is given by

\footnotetext{
${ }^{8}$ Throughout the paper, lowercase denotes $\operatorname{logs}$, such that $x=\ln (X)$.
} 


$$
\frac{\partial S_{i t}}{\partial K_{i t}}=\beta_{K} \frac{\Omega_{i t} K_{i t}^{\beta_{K}} L_{i t}^{\beta_{L}} M_{i t}^{\beta_{M}}}{K_{i t}} .
$$

We will frequently refer to the marginal revenue product of capital (MRPK), which we measure in logs:

$$
\begin{aligned}
\operatorname{MRPK}_{i t} & =\log \left(\beta_{K}\right)+\log \left(S_{i t}\right)-\log \left(K_{i t}\right) \\
& =\log \left(\beta_{K}\right)+s_{i t}-k_{i t} .
\end{aligned}
$$

The marginal revenue products of labor and materials are defined similarly. ${ }^{9}$

Our notion of productivity is a revenue-based productivity measure, or TFPR (as introduced by Foster, Haltiwanger, and Syverson [2008]). As is common in this literature, we do not separately observe prices and quantities at the producer level, and therefore, we can only directly recover a measure of profitability or sales per input precisely.

This implies that all our statements about productivity refer to TFPR, and therefore, deviations across producers in our measure of productivity, or its covariance with firm size, could reflect many types of distortion, such as adjustment costs, markups, or policy distortions, as Hsieh and Klenow (2009) discuss in detail.

\section{B. A Dynamic Investment Model}

We now articulate a dynamic investment model that allows us to examine the link between TFPR volatility and dispersion in both the static marginal revenue product of capital and other variables of interest. Our model follows, and builds on, a standard model of investment used in the work of Dixit and Pindyck (1994), Caballero and Pindyck (1996), Cooper and Haltiwanger (2006), and Bloom (2009)..$^{10}$

Taking the structure in Section II.A as given, we begin by assuming that firms can hire labor in each period for a wage $p_{L}$ and acquire materials in each period at a price $p_{M}$. Both of these inputs have no additional adjustment costs. Thus, conditional on $\Omega_{i t}$ and $K_{i t}$, we can substitute in the statically optimal amount of labor and materials. This leads to a "period profit" (ignoring capital costs for the moment) of

\footnotetext{
${ }^{9}$ Owing to the Cobb-Douglas specification, the marginal and average products are equivalent in our setup. Hence, in the data we measure the average product and, using the model, interpret it as marginal.

${ }^{10}$ The model used in this paper is a partial equilibrium model that can be rationalized from a general equilibrium perspective only if there are no aggregate shocks and a continuum of firms. Bloom et al. (2012) discuss the implications of putting this type of model into a general equilibrium framework with aggregate shocks vs. using a partial equilibrium model.
} 


$$
\pi\left(\Omega_{i t}, K_{i t}\right)=\lambda \Omega_{i t}^{1 /\left(\beta_{K}+\epsilon^{-1}\right)} K_{i t}^{\beta_{K} /\left(\beta_{K}+\epsilon^{-1}\right)},
$$

where

$$
\lambda=\left(\beta_{K}+\epsilon^{-1}\right)\left(\frac{\beta_{L}}{p_{L}}\right)^{\beta_{L} /\left(\beta_{K}+\epsilon^{-1}\right)}\left(\frac{\beta_{M}}{p_{M}}\right)^{\beta_{M} /\left(\beta_{K}+\epsilon^{-1}\right)} .
$$

Capital depreciates at rate $\delta$ so $K_{i t+1}=(1-\delta) K_{i t}+I_{i t}$, where $I_{i t}$ denotes investment. These investment decisions are affected by a one-period time to build and a cost of investment $C\left(I_{i t}, K_{i t}, \Omega_{i t}\right)$.

We employ an adjustment cost function composed of (1) a fixed disruption cost of investing and (2) a convex adjustment cost expressed as a function of the percent investment rate. Formally,

$$
C\left(I_{i t}, K_{i t}, \Omega_{i t}\right)=I_{i t}+C_{K}^{F} \mathbf{1}(\cdot)\left\{I_{i t} \neq 0\right\} \pi\left(\Omega_{i t}, K_{i t}\right)+C_{K}^{Q} K_{i t}\left(\frac{I_{i t}}{K_{i t}}\right)^{2} .
$$

Next, let $\omega_{i t}$ follow an $\operatorname{AR}(1)$ process given by

$$
\omega_{i t}=\mu+\rho \omega_{i t-1}+\sigma \nu_{i t}
$$

where $\nu_{i t} \sim \mathcal{N}(0,1)$ is an independent and identically distributed (i.i.d.) standard normal random variable. This implicitly defines the transition function of $\Omega: \phi\left(\Omega_{i t+1} \mid \Omega_{i t}\right)$.

A firm's value function $V$ is given by the Bellman equation

$$
\begin{aligned}
V\left(\Omega_{i t}, K_{i t}\right)= & \max _{I_{i t}} \pi\left(\Omega_{i t}, K_{i t}\right)-C\left(I_{i t}, K_{i t}, \Omega_{i t}\right) \\
& +\beta \int_{\Omega_{i t+1}} V\left(\Omega_{i t+1}, \delta K_{i t}+I_{i t}\right) \phi\left(\Omega_{i t+1} \mid \Omega_{i t}\right) d \Omega_{i t+1},
\end{aligned}
$$

and, thus, a firm's policy function $I^{*}\left(\Omega_{i t}, K_{i t}\right)$ is just the investment level that maximizes the firm's continuation value less the cost of investment.

Note that since there is neither entry nor exit in this model, there is no truncation of the TFPR distribution. ${ }^{11}$ Thus, given the AR(1) structure above, the cross-sectional standard deviation of TFPR is

11 The absence of entry and exit is a consequence of the decreasing returns to scale in the revenue equation (yielded by constant returns to scale in the production function and an elastic demand curve) and the absence of fixed costs, which make it profitable for any firm to operate at a small enough scale. See Midrigan and Xu (2014) for a discussion of the role of entry and exit in a similar model. 


$$
\mathrm{SD}\left(\omega_{i t}\right)=\frac{\sigma}{\sqrt{1-\rho^{2}}}
$$

(see Hamilton 1994, 53).

\section{Moments of Interest}

In examining the data we will focus on a set of moments that can be generated by the model, three of which warrant explicit definitions. For ease of reference, we provide these definitions here.

The first moment is the dispersion in the (static) marginal revenue product of capital (MRPK, as defined in eq. [5]). Dispersion in MRPK is defined as $\mathrm{SD}_{s t}\left(\mathrm{MRPK}_{i t}\right)$, where the st subscript indicates that the standard deviation is taken within industry-country $s$ in year $t$. This will be our most common specification, although at times we will use different configurations (indicated in the subscript).

We next define the computed volatility in the static marginal revenue product of capital over time as

$$
\mathrm{SD}_{s t}(\Delta \mathrm{MRPK})=\mathrm{SD}_{s t}\left(\mathrm{MRPK}_{i t}-\mathrm{MRPK}_{i t-1}\right) .
$$

Third, the volatility in firms' capital over time is defined as

$$
\mathrm{SD}_{s t}(\Delta k)=\mathrm{SD}_{s t}\left(k_{i t}-k_{i t-1}\right) \text {. }
$$

It is important to note that the magnitudes of these three moments are unchanged if we adopt an alternative specification of the model in which each firm's TFPR process has a firm-specific fixed effect, that is, if $\mu$ is firm specific. This result is established formally in theorem 1 in Appendix A. At the heart of the result is the property that a different constant term in the $\operatorname{AR}(1)$ results in a level shift in the process, and this generates level shifts in the inputs $(K, L$, and $M)$. These level shifts then get canceled out when taking differences at the firm level.

\section{Comparative Statics}

We analyze the model using computation. Like Bloom (2009), we use a model in which investment decisions are made each month (a period in the model). Modeling decisions at a monthly level is an attractive approach, as the model incorporates the likely time aggregation embedded in annual data. ${ }^{12}$ The results we report are in terms of what one would

${ }^{12}$ This interpretation requires transforming the AR(1) process - which is quoted to reflect, and empirically estimated off, annual data - into its monthly equivalent. After noting that the sum of normal random variables with the same mean is distributed normally, this reduces to a straightforward algebraic exercise. 


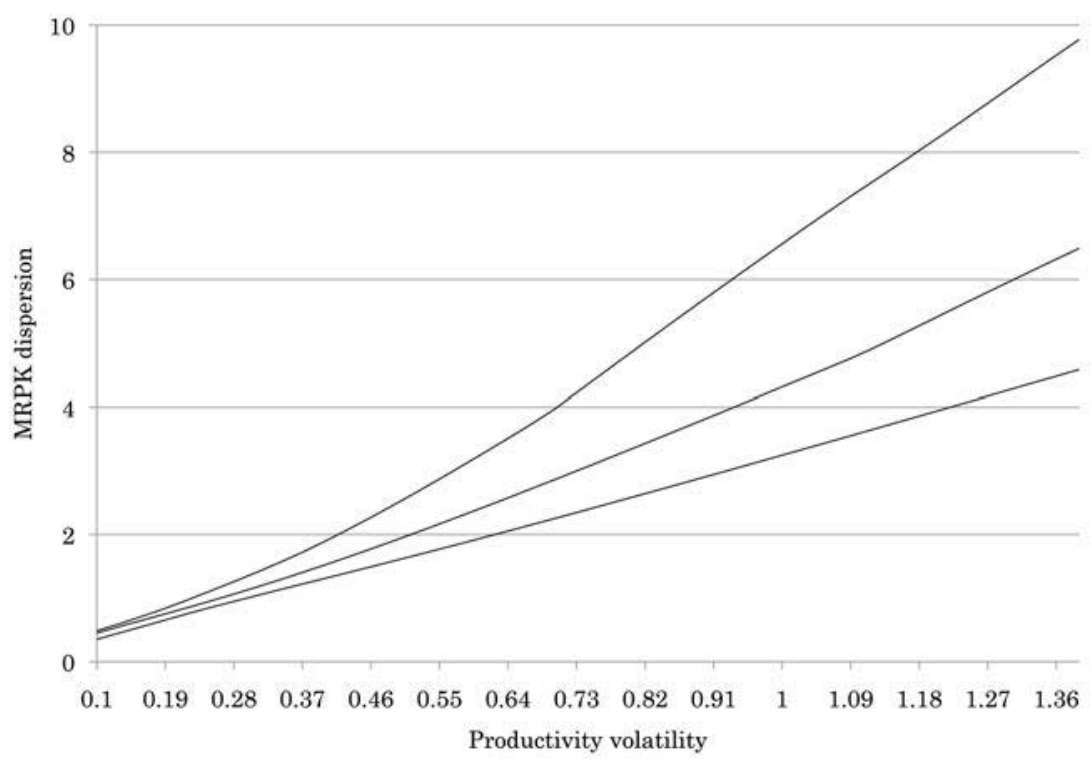

FIG. 1.-MRPK dispersion and volatility: model simulation. Values used in this simulation are $\epsilon=-4, \delta=10$ percent, $\beta=1 /(1+0.065), \beta_{K}=0.12, \beta_{M}=0.40, \beta_{L}=0.23$, $C_{K}^{F}=0.09, C_{K}^{Q}=8.8, \lambda=1, \mu=0, \rho \in\{0.65,0.85,0.94\}$ (corresponding to the lines from bottom $[0.65]$ to top [0.94]), and $\sigma \in[0.1,1.4]$. We use the means in the US census data to get our $\beta$ 's and use estimates of adjustment costs for the United States discussed in Section V.

see in annual data; that is, we aggregate up from monthly decision making to the year.

Figure 1 examines the way $\mathrm{SD}_{s t}(\mathrm{MRPK})$, the dispersion in the static marginal revenue product of capital, changes as $\sigma$, the volatility of TFPR, changes. For $\rho=0$, we can show that $\mathrm{SD}_{s t}(\mathrm{MRPK})=\left[1 /\left(\beta_{K}+\epsilon^{-1}\right)\right] \sigma$. Thus more volatility of productivity leads to higher-dispersion MPRK. This result is straightforward to show since, with $\rho=0$, productivity is no longer a state, and firms choose the same steady-state level of capital (for a similar model, see Lucas [1967]). Where $\rho \neq 0$, we use the computational simulations in the paper to establish the possibility that volatility increases misallocation. ${ }^{13}$

To generate this figure, we use parameters estimated using US census data as described in Section V. Parameters and details of computation can be found in Appendix C. In the figure there are three lines that correspond to the model with both a one-period time to build and ad-

${ }^{13}$ For $\rho \neq 0$, this problem becomes substantially more complex. The issue is that the sales to capital ratio now depends on the correlation between $K$ and $\Omega$. In this broad class of models, whether investment is increasing or decreasing in volatility is ambiguous (see, e.g., Caballero and Pindyck 1993). Whether investment is increasing in productivity is also unclear: see theorem 27 in Pakes (1996). 
justment costs, but with different persistence parameters in the $\operatorname{AR}(1)$ process. From top to bottom, these lines correspond to $\rho$ equal to 0.94 , 0.85 , and 0.65 , respectively. ${ }^{14}$ Note that, for any specification and any level of $\rho$, as $\sigma$ increases, so does dispersion in the static marginal revenue product of capital.

To further understand the pattern in figure 1 , note that this dispersion reflects the optimal investment choices of firms facing different TFPR shocks over time and, hence, different state variables. To make the effect of this clear, note that if all firms had the same capital stock, this graph would contain a series of upward-sloping straight lines out of the origin. Yet (focusing on the solid black lines) the relationship between $\mathrm{SD}_{s t}(\mathrm{MRPK})$ and $\sigma$ is not linear and has a slope change in the region of $\sigma=0.5$ for $\rho=0.94$ and in a (wider) region around $\sigma=0.6$ for $\rho=0.85$. There is no readily discernible slope change in this range of $\sigma$ for $\rho=0.65$.

To see why this is happening, note that initially, as volatility increases, firms will engage in more investment and disinvestment. Since greater volatility leads to larger changes in TFPR, it is natural that firms respond by altering their capital stock more frequently. However, past a certain point, firms begin to reduce their response to TFPR shocks. This begins as $\sigma$ approaches 0.5 for $\rho=0.94$ and 0.6 for $\rho=0.85$, while for $\rho=0.65$, the same pattern exists but is much more gradual.

At these high levels of volatility, current TFPR is a weaker signal of the future marginal value of capital. Hence, firms respond less to shocks today because those current shocks are more likely to be swamped by future shocks. In the limit, where the TFPR process is an i.i.d. draw, current TFPR provides no information about future profitability. Firms would choose an optimal level of capital and stick to it forever, resulting in no variance in investment across firms. Thus, the slope changes evident in the relationships in figure 1 reflect a flattening out of capital adjustments to volatility.

\section{Data and Measurement}

\section{A. Data}

We employ multiple data sets in our analysis. Table 1 describes the tier 1 data. They consist of country-specific producer-level data from eight countries: the United States, Chile, France, India, Mexico, Romania, Slovenia, and Spain. Each of these data sets has been used extensively in the literature, most commonly in the analysis of productivity (see, e.g., Tybout and

${ }^{14}$ These three values of $\rho$ represent the 90th percentile, median, and 10th percentile in the US census data, respectively. 


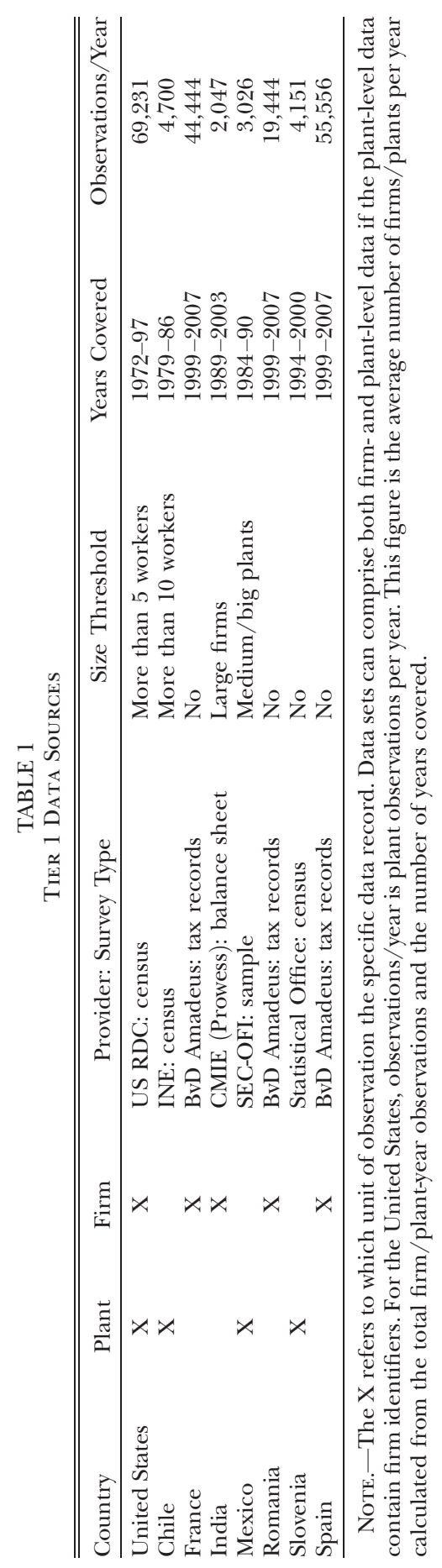


Westbrook 1995; Roberts 1996; Pavcnik 2002; Konings and Vandenbussche 2005; De Loecker and Konings 2006; De Loecker 2007; Goldberg etal. 2009; Bloom, Draca, and Van Reenen 2011).

The data sets differ in the time period covered and in how producers are sampled. Table 1 summarizes the main features of the various data sets. Below we briefly discuss the various tier 1 data sets and defer more details to Appendix B.

United States.-The data for the United States come from the US Census Bureau's Research Data Center Program. We use data on manufacturing plants from the Census of Manufactures (henceforth, CMF) and the Annual Survey of Manufacturers (henceforth, ASM) from 1972 to 1997. The CMF sends a questionnaire to all manufacturing plants in the United States with more than five employees every 5 years, while the ASM is a 4-year rotating panel with replacement, sent to approximately a third of manufacturing plants, with large plants being overrepresented in the sampling scheme. The final data set contains 735,342 plants over a 26 -year period.

An industry is defined as a four-digit Standard Industrial Classification (SIC) code. Labor is measured using the total number of employees at the plant. Materials are measured using total cost of parts and raw materials.

Capital is constructed in two ways. For the majority of plants, including all plants in the CMF, capital is measured using a question on total assetsbe they machines or buildings - at the plant. For the remaining observations, capital is constructed using the perpetual inventory method, using industry-specific depreciation rates and investment deflators from the Bureau of Economic Analysis and the National Bureau of Economic Research. Capital, materials, and sales are deflated using the NBER-Center for Economic Studies industry-level deflators into 1997 dollars.

Chile.-Annual plant-level data on all manufacturing plants with at least 10 workers were provided by Chile's Instituto Nacional de Estadistica. These data, which cover the period 1979-86, include production, employment, investment, intermediate input, and balance sheet variables. Industries are classified according to their four-digit International Standard Industrial Classification industry code. The data contain 37,600 plant-year observations. The smallest number of plants observed in any year is 4,205 in 1983 .

France, Romania, and Spain.-Annual firm-level data on manufacturing firms for France, Romania, and Spain are obtained from Bureau Van Dijck's (BvD) Amadeus data set and cover firms reporting to the local tax authorities or data collection agencies for the period between 1999 and 2007. We selected three relatively large European countries at different stages of economic development. The coverage for all three countries is substantial in that we cover approximately 90 percent of economic activity in each of the three manufacturing sectors. For example, for France in 2000, we record total sales of $€ 739$ billion, whereas the Organization 
for Economic Cooperation and Development reports total sales to be $€ 768$ billion. This implies coverage of 96 percent of total economic activity in manufacturing. For Spain we find, using the same coverage calculation, coverage of 88 percent. The collection protocol of $\mathrm{BvD}$ is consistent across countries. We focus on the manufacturing sector to facilitate the measurement of TFPR. Industries are classified according to the two-digit NACE (revision 1.1) code for all three countries. Our data cover firms that are primarily active in sectors NACE 15-36. This leaves us with 391,422, 174,435, and 457,934 firm-year observations for France, Romania, and Spain, respectively. The data include standard production data, including sales, employment, investment, intermediate input, and other balance sheet variables.

India.-Annual firm-level data on manufacturing firms were provided by Prowess and are collected by the Centre for Monitoring the Indian Economy. Prowess is a panel that tracks firms over time for the period 1989-2003. The data contain mainly medium and large Indian firms. Industries are classified according to the four-digit PNIC (the Indian industrial classification code). These data include sales, employment, investment, capital, intermediate input, and various balance sheet variables. ${ }^{15}$ The final data set comprises 30,709 firm-year observations.

Mexico.-Annual plant-level data on manufacturing plants are recorded by Mexico's Annual Industrial Survey and are provided by Mexico's Secretary of Commerce and Industrial Development. These data, which cover the period 1984-90, include production, employment, investment, intermediate input, and balance sheet variables. The sample of plants represents approximately 8 percent of total output, where the excluded plants are the smallest ones. Industries are classified according to the Mexican Industrial Classification (a four-digit industrial classification system). The final data contain 21,180 plant-year observations. The minimum number of observed firms in a year is 2,958 in 1989.

Slovenia.-The data are taken from the Slovenian Central Statistical Office and are the full company accounts of firms operating in the manufacturing sector between 1994 and 2000. We have information on 7,915 firms: an unbalanced panel with information on production, employment, investment, intermediate input, and balance sheet variables. Industries are classified according to the two-digit NACE revision 1.1 code.

\section{B. Measurement}

To guide the measurement of TFPR, we build on the model in Section II. A and, in particular, rely on the sales-generating production function in equation (3). In order to recover a measure of TFPR, $\omega_{i t}$, we need to

\footnotetext{
${ }^{15}$ The Indian data do not report the wage bill separately from the number of workers. We do, however, take care to appropriately deflate the wage bill.
} 
compute the values of $\beta_{L}, \beta_{M}$, and $\beta_{K}$ by industry-country. Profit maximization implies that for each input facing no adjustment costs, the revenue production function coefficient equals the share of the input's expenditure in sales, or formally,

$$
\beta_{X}=\frac{P_{i t}^{X} X_{i t}}{S_{i t}} \quad \text { for } X \in\{L, M\} .
$$

As mentioned before, we allow $\beta_{X}$ to vary at the industry level within a country, thereby allowing the production function to vary across industries and countries. In practice, in order to obtain a robust measure of these shares, we rely on the median of the expenditure share for labor and intermediate inputs, in a given industry-country $(s c)$, or

$$
\beta_{X}^{s c}=\operatorname{median}\left(\left\{\frac{P_{i t}^{X} X_{i t}}{S_{i t}}\right\}\right) \text { for } X \in\{L, M\}, i \in s c .
$$

To recover the coefficient on capital, $\beta_{K}$, we use our assumption of constant returns to scale in production, that is, $\Sigma_{x} \alpha_{x}=1$, such that

$$
\beta_{K}=\frac{\epsilon-1}{\epsilon}-\beta_{L}-\beta_{K} .
$$

In order to compute $\beta_{K}$, we need to assign a value to the elasticity parameter, $\epsilon$. We follow Bloom (2009) and set it equal to four. However, our main findings are invariant to choosing different values for the elasticity of demand in the range $[4-8] .{ }^{16}$

Finally, to compute TFPR, we simply plug in the coefficients obtained above into equation (16) below and compute for each individual firm in a given industry-country pair:

$$
\omega_{i t}=s_{i t}-\beta_{K} k_{i t}-\beta_{L} l_{i t}-\beta_{M} m_{i t} .
$$

For a small fraction of the industry-country pairs for which the sum of the labor and material coefficients exceeds $(\epsilon-1) / \epsilon=0.75$, and thus would imply a negative capital coefficient, we proceed by using the relevant country's average coefficient. For the one country, Slovenia, for which the average material coefficient is above 0.75 , we rely on ordinary least squares (OLS) production function coefficients, effectively using the average output elasticities. ${ }^{17}$ Importantly, this approach in inferring

${ }^{16}$ Table D.6 in the online appendix presents these results.

${ }^{17}$ Alternatively, we could estimate the output elasticity directly from production data. We follow the standard in this literature and rely on cost shares to compute TFPR and thereby avoid the issues surrounding identification of output elasticities (in our case, across many industries and countries). 
$\beta_{K}$ allows capital to have adjustment costs since it does not rely on a static first-order condition for capital. ${ }^{18}$

To measure the sales-generating production function coefficients, and subsequently TFPR $\left(\omega_{i t}\right)$, we require a measure of firm-level sales $\left(S_{i t}\right)$, employment $\left(L_{i t}\right)$, material use $\left(M_{i t}\right)$, and the capital stock $\left(K_{i t}\right)$. We follow the approach to measurement described in Bartelsman et al. (2013), which uses data sources comparable to those we use. When measuring the value of the capital stock, we either construct the capital series from the investment data or directly observe the book value of a producer's tangible fixed assets. We deflate all output and input data with the relevant country-industry-specific producer price deflators.

We provide summary statistics describing our data sets in table 2. In panel A, we report the median number of workers and median sales and TFPR growth. Panel B lists the various standard deviations that are of direct interest for our analysis: dispersion in MRPK, dispersion in capital and TFPR, and a simple measure of volatility given by $\operatorname{SD}\left(\omega_{i t}-\omega_{i t-1}\right)$.

As expected, the median size varies substantially across the various data sets because of different data collection protocols. ${ }^{19}$ Productivity growth varies across countries, and it is no surprise that Slovenia and India are the fastest-growing economies. The dispersion in MRPK ranges from 0.98 in the United States to 1.56 in Slovenia. The next section examines the relationship between dispersion in MRPK and volatility, a central implication of our model, in more detail.

\section{Reduced-Form Evidence}

\section{A. Main Results}

We begin our analysis by plotting, in figure 2 , the relationship between the dispersion in MRPK and volatility of TFPR for the US census data, with each dot on the graph representing a specific four-digit SIC code. We start with the US census data since this is the richest data source we have access to and the data set in which issues of measurement and sampling frame are plausibly the least important. We find a striking positive relationship between volatility of TFPR and MRPK dispersion.

To see if the relationship between MRPK dispersion and volatility of TFPR holds up more generally, table 3 presents, for each of our tier 1 data

\footnotetext{
${ }^{18}$ See De Loecker and Warzynski (2012, sec. 2.A) for more discussion. Similarly, we could use a value-added rather than gross output approach to measurement. Doing so does not change the results. Table D.17 in the online appendix presents the results of our main specification relying on value added-based production functions.

${ }^{19}$ In table D.5 in the online appendix, we verify the robustness of our results to using a common size threshold.
} 
TABLE 2

Summary Statistics across Tier 1 Data Sets

\begin{tabular}{|c|c|c|c|c|c|c|c|}
\hline \multirow[b]{2}{*}{ COUNTRY } & \multicolumn{3}{|c|}{ A. Medians } & \multicolumn{4}{|c|}{ B. Standard Deviations } \\
\hline & Workers & $\Delta s$ & $\Delta \omega$ & $\begin{array}{c}\text { Dispersion } \\
\text { MRPK }\end{array}$ & Dispersion $k$ & Dispersion $\omega$ & Volatility \\
\hline United States $^{\mathrm{a}}$ & 111 & .01 & .00 & .98 & 1.78 & .63 & .35 \\
\hline Chile & 19 & .02 & .00 & 1.22 & 1.92 & .54 & .29 \\
\hline France & 8 & .02 & .02 & 1.28 & 2.04 & .61 & .19 \\
\hline India & NA & .06 & .04 & 1.13 & 1.61 & .67 & .29 \\
\hline Mexico & 141 & .02 & .02 & 1.40 & 2.13 & .86 & .39 \\
\hline Romania & 5 & .01 & .01 & 1.38 & 2.05 & .70 & .39 \\
\hline Slovenia & 4 & .07 & .03 & 1.56 & 2.51 & .59 & .40 \\
\hline Spain & 8 & .03 & .01 & 1.48 & 2.00 & .46 & .23 \\
\hline
\end{tabular}

NotE.-Dispersion MRPK is given by $\operatorname{SD}\left(\mathrm{MRPK}_{i t}\right)$, and volatility is $\operatorname{SD}\left(\omega_{i t}-\omega_{i t-1}\right)$; i.e., we compute dispersion across the entire data set.

a The median is computed for the US census data as the average of plants between the 48th and 52nd percentiles.

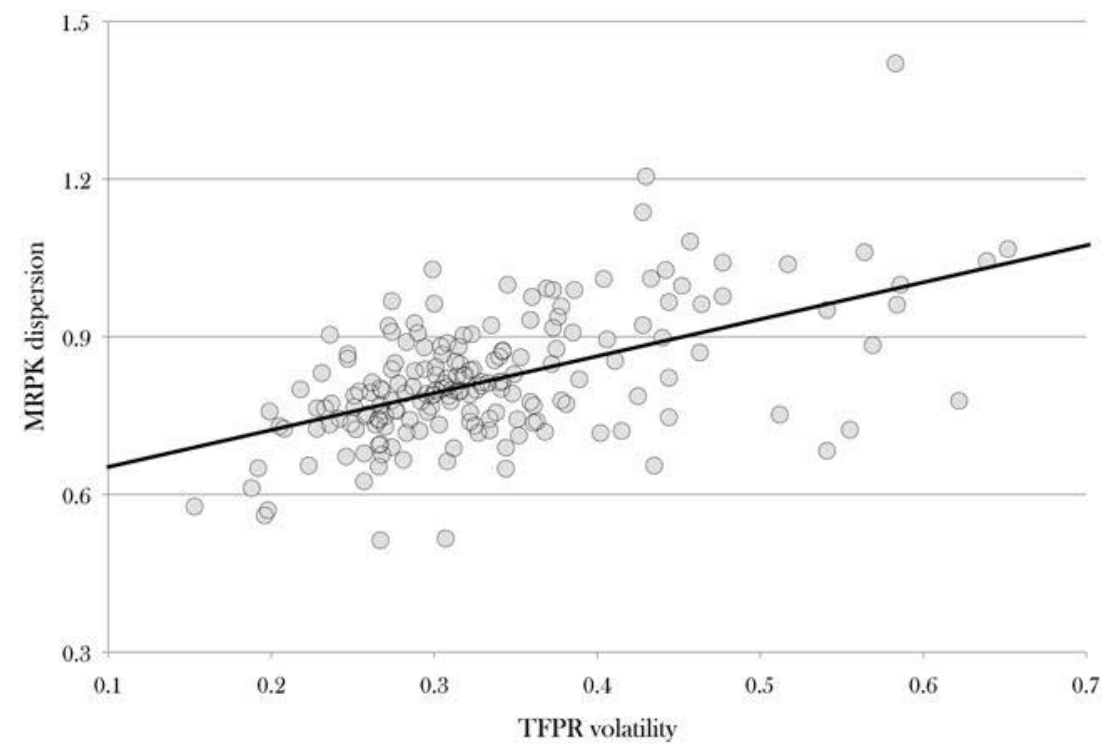

FIG. 2.- Volatility and the dispersion in MRPK: US plant data, 1972-97. The unit of observation is the industry. The line is generated by an OLS regression on 188 industries, in which the estimated slope is $0.73(0.08)$ and the constant is $0.57(0.03)$, and the $R^{2}=.3$, where the standard errors are in parentheses.

sets, regressions of the dispersion in MRPK, on TFPR volatility, controlling for industry fixed effects. The focus of table 3 is the set of country-specific regressions, where the unit of observation is the industry-year. The last two regressions pool the data, such that the unit of observation is the industrycountry-year. 
TABLE 3

DisPERSION MRPK AND VOLATILITY

\begin{tabular}{|c|c|c|c|}
\hline Country & Coefficient & $R^{2}$ & $\begin{array}{l}\text { Industry-Year } \\
\text { Observations }\end{array}$ \\
\hline \multicolumn{4}{|l|}{ United States: } \\
\hline Plants & $\begin{array}{l}.76^{* * * *} \\
(.04)\end{array}$ & .47 & 4,037 \\
\hline Firms & $\begin{array}{l}.68^{* * * *} \\
(.07)\end{array}$ & .44 & 4,037 \\
\hline Chile & $\begin{array}{l}.54^{*} \\
(.29)\end{array}$ & .13 & 55 \\
\hline France & $\begin{array}{l}1.03^{* * * *} \\
(.33)\end{array}$ & .28 & 167 \\
\hline India & $\begin{array}{l}.61^{* *} \\
(.17)\end{array}$ & .28 & 279 \\
\hline Mexico & $\begin{array}{l}.19 * * \\
(.07)\end{array}$ & .07 & 296 \\
\hline Romania & $\begin{array}{l}.44^{* * * *} \\
(.13)\end{array}$ & .21 & 126 \\
\hline Slovenia & $\begin{array}{l}.53 * * \\
(.21)\end{array}$ & .09 & 108 \\
\hline Spain & $\begin{array}{l}.56^{*} \\
(.33)\end{array}$ & .35 & 181 \\
\hline \multicolumn{4}{|l|}{ All: } \\
\hline Unweighted & $\begin{array}{l}.55 * * * \\
(.15)\end{array}$ & .67 & 5,326 \\
\hline Weighted & $\begin{array}{l}.74^{* * * *} \\
(.03)\end{array}$ & .50 & 5,326 \\
\hline
\end{tabular}

Note.-We report the coefficient of a regression of $\mathrm{SD}_{s t}(\mathrm{MRPK})$ against volatility, defined as $\mathrm{SD}_{s t}\left(\omega_{i t}-\omega_{i t-1}\right)$, including year dummies. Standard errors are clustered at the industry level. For all countries, weighted regression includes as weights the number of producers in a country-industryyear observation. These cross-country-industry-year regressions include year and country dummies and report standard errors (in parentheses) clustered at the country level. Table D.15 in the online appendix reports the regression coefficients for the United States using only variation across industries. This is directly related to fig. 2.

* Significant at the 10 percent level.

** Significant at the 5 percent level.

*** Significant at the 1 percent level.

For each of the countries, there is a positive, and significant, coefficient. Notably, in the US census, we see coefficients of 0.76 (using plant-level data) and 0.68 (using firm-level data), both of which are significant at the 1 percent level. Since we observe no economically significant difference between plant- and firm-level data using the US census, from this point on, we use plant-level data in computing US numbers.

These country-specific regressions are consistent with the model prediction that dispersion in the static marginal revenue product of capital, at the country-industry level, should be positively correlated with the volatility of TFPR shocks. 
Pooling across countries, we see the same pattern. The reported coefficients are 0.55 , when the data are pooled in an unweighted way, and 0.74 , when the weighting matrix accounts for the number of industryyear observations in a country. Figure $4 A$ below plots the dispersion in static marginal revenue product of capital against volatility. While the number of countries is very limited, it suggests a positive relationship between both variables.

An important element in these regressions is the measurement of volatility. In table 3 we measure volatility by $\mathrm{SD}_{s t}\left(\omega_{i t}-\omega_{i t-1}\right)$. This allows the shock process to vary over time but is not an exact replication of the $\mathrm{AR}(1)$ process posited in the model. In what follows we assess the sensitivity of these baseline results to alternative specifications of the TFPR shock process. ${ }^{20}$

Table 4 takes alternative measures of the volatility of the TFPR process and runs country-specific regressions mirroring those presented in table 3 . The three measures used are $\operatorname{SD}_{s}\left(\omega_{i t}-\omega_{i t-1}\right)$; an $\operatorname{AR}(1)$ measure, which is the $\sigma_{s}$ term in the specification $\omega_{i t}=\mu_{s}+\rho_{s} \omega_{i t-1}+\sigma_{s} \nu_{i t}$; and, finally, an $\operatorname{AR}(1)$ specification in which we replace $\mu_{s}$ with producer-level fixed effects. In table 4 we refer to this last specification as $\mathrm{AR}(1) \mathrm{FE}$. The $\mathrm{AR}(1)$ specifications impose the restriction that $\sigma_{s}$ is constant over time. To keep our alternative measures comparable, we impose the same restriction on our previous measure of volatility, $\mathrm{SD}_{s}\left(\omega_{i t}-\omega_{i t-1}\right) .^{21}$ These volatility measures are highly positively correlated. The correlation coefficient for any pair of measures, for any country, exceeds .72 and is often above $.9{ }^{22}$

In all regressions the coefficient on volatility is positive, and in all but two cases - out of 24 - the coefficient is significant at the 10 percent level or better. In addition, the magnitudes of the coefficients are comparable across all specifications, although the AR(1)FE specification tends to produce coefficients that are somewhat higher than the other two specifications. This is likely due to some of the $\sigma_{s}$ variation being absorbed by the producer fixed effect.

Overall, the results support the conclusion that the qualitative reducedform patterns observed in the baseline specification (table 3) are robust to alternative specifications of the TFPR process.

\section{B. Additional Implications}

So far we have focused on the relationship between the dispersion in MRPK and volatility of TFPR. Although this is the main prediction of

\footnotetext{
${ }^{20}$ Note that the specification for our $\mathrm{AR}(1)$ process rules out aggregate-level shocks to TFPR growth. However, a regression of changes in TFPR on country-year dummies yields $R^{2}$ 's between .001 for Mexico and .023 for Chile when running TFPR growth against year dummies. Thus, there appears to be only a small aggregate component to TFPR change.

${ }^{21}$ As a consequence, the results in table 3 (at the country-industry-year level) differ in magnitude from those presented in table 4 (at the country-industry level).

${ }_{22}$ Table D.4 in the online appendix reports these statistics.
} 
TABLE 4

DisPERSION OF MRPK AND VOLATILITY OF TFPR: RoBustness

\begin{tabular}{lclc}
\hline \hline & \multicolumn{3}{c}{ Volatility Measure } \\
\cline { 2 - 4 } Country & $\mathrm{SD}_{s}\left(\omega_{i t}-\omega_{i t-1}\right)$ & $\mathrm{AR}(1)$ & $\mathrm{AR}(1) \mathrm{FE}$ \\
\hline United States & $.82^{* * *}$ & $.86^{* * *}$ & $1.24^{* * *}$ \\
& $(.04)$ & $(.07)$ & $(.11)$ \\
Chile & $1.48^{*}$ & $2.10^{* * *}$ & .33 \\
& $(.65)$ & $(.65)$ & $(1.48)$ \\
France & $1.73^{* * *}$ & $1.75^{* * *}$ & $2.55^{* * *}$ \\
& $(.41)$ & $(.41)$ & $(.61)$ \\
India & $1.31^{* * *}$ & $1.75^{* * *}$ & $2.75^{* * *}$ \\
& $(.33)$ & $(.39)$ & $(.55)$ \\
Mexico & $.39^{*}$ & $.41^{* *}$ & .33 \\
& $(.17)$ & $(.17)$ & $(.25)$ \\
Romania & $.76^{* * *}$ & $.94^{* * *}$ & $1.38^{*}$ \\
& $(.23)$ & $(.36)$ & $(.72)$ \\
Slovenia & $2.73^{* * *}$ & $2.47^{* * *}$ & $3.47^{* * *}$ \\
\multirow{2}{*}{ Spain } & $(.41)$ & $(.41)$ & $(.69)$ \\
& $1.24^{* * *}$ & $1.46^{* * *}$ & $2.55^{* * *}$ \\
& $(.34)$ & $(.44)$ & $(.59)$ \\
\hline
\end{tabular}

Note.-We report the coefficient of a regression of $\mathrm{SD}_{\mathrm{st}}(\mathrm{MRPK})$ against alternative measures of volatility, defined in the text. Standard errors (in parentheses) are clustered at the industry level.

* Significant at the 10 percent level.

** Significant at the 5 percent level.

*** Significant at the 1 percent level.

our model, there are a number of additional implications, at both the individual producer and aggregate levels. We explore these below.

\section{Individual Producer Implications}

An essential prediction of our model is that adjustment costs in capital, coupled with TFPR shocks, lead to differences in MRPK among producers. The model thus implies that once producers install capital, TFPR shocks should manifest themselves in variation in MRPK across producers. In the absence of adjustment costs-including a one-period time to build-producers could simply adjust their capital, and this would lead to the equalization of MRPK across producers. To test this mechanism, we run the following regression for each of our tier 1 countries:

$$
\operatorname{MRPK}_{i t}=\gamma_{0}+\gamma_{1} \xi_{i t}+\gamma_{2} k_{i t}+\gamma_{3} \omega_{i t-1}+\gamma_{t}+\gamma_{s}+\nu_{i t},
$$

where $\xi_{i t} \equiv \omega_{i t}-\omega_{i t-1}$ is the "shock" in TFPR between $t$ and $t-1$. From our one-period time-to-build assumption, this shock has not been observed when the firm makes its investment decision about capital stock $k_{i t}$ at time $t-1$. We also condition on lagged TFPR to make sure we compare two firms with the same TFPR at $t-1$ making the same capital decision, and we ask whether their MRPK is different if they are hit by different TFPR shocks $\xi_{i t}$. Our theory predicts a positive coefficient for 
TABLE 5

Additional Predictions: MRPK against Shocks to TFPR

\begin{tabular}{|c|c|c|c|}
\hline Country & Shock & Shock AR(1) & Shock AR(1)FE \\
\hline United States & $\begin{array}{l}1.29 * * * \\
(.00)\end{array}$ & $\begin{array}{l}1.26 * * * \\
(.00)\end{array}$ & $\begin{array}{l}1.13 * * * \\
(.01)\end{array}$ \\
\hline Chile & $\begin{array}{l}1.42 * * * \\
(.02)\end{array}$ & $\begin{array}{l}1.42 * * * \\
(.02)\end{array}$ & $\begin{array}{l}1.04 * * * \\
(.02)\end{array}$ \\
\hline France & $\begin{array}{l}1.37 * * * \\
(.01)\end{array}$ & $\begin{array}{l}1.37 * * * \\
(.01)\end{array}$ & $\begin{array}{l}1.26 * * * \\
(.01)\end{array}$ \\
\hline India & $\begin{array}{l}1.32 * * * \\
(.04)\end{array}$ & $\begin{array}{l}1.32 * * * \\
(.04)\end{array}$ & $\begin{array}{l}1.16^{* * * *} \\
(.04)\end{array}$ \\
\hline Mexico & $\begin{array}{l}1.07 * * * \\
(.04)\end{array}$ & $\begin{array}{l}1.07 * * * \\
(.04)\end{array}$ & $\begin{array}{l}.67 * * * \\
(.05)\end{array}$ \\
\hline Romania & $\begin{array}{l}1.31 * * * * \\
(.01)\end{array}$ & $\begin{array}{l}1.31 * * * * \\
(.01)\end{array}$ & $\begin{array}{l}1.12 * * * \\
(.01)\end{array}$ \\
\hline Slovenia & $\begin{array}{l}1.65^{* * * *} \\
(.04)\end{array}$ & $\begin{array}{l}1.64^{* * * *} \\
(.04)\end{array}$ & $\begin{array}{l}1.48^{* * * *} \\
(.04)\end{array}$ \\
\hline Spain & $\begin{array}{l}1.28 * * * \\
(.01)\end{array}$ & $\begin{array}{l}1.28 * * * \\
(.01)\end{array}$ & $\begin{array}{l}.69^{* * * *} \\
(.01)\end{array}$ \\
\hline
\end{tabular}

NoTE.-We run, by country, $\ln$ (MRPK) against the TFPR shock, capital, lagged TFPR, and year and industry fixed effects. The TFPR shock is given by $\xi_{i t} \equiv \omega_{i t}-E\left(\omega_{i t} \mid \mathcal{I}_{i t-1}\right)$, where $\mathcal{I}_{i t-1}$ is the information set of producer $i$ at time $t-1$; depending on the TFPR process, we consider that this contains lagged TFPR and producer and year fixed effects. We suppress the coefficients on capital and lagged TFPR (they are significant with negative and positive signs, respectively, everywhere) and also suppress the fixed effects on year and industry. The standard errors (in parentheses) are clustered at the firm/ plant level to account for serially correlation and heteroskedasticity.

*** Significant at the 1 percent level.

$\gamma_{1}$. The null hypothesis, given by the static model, is no meaningful dispersion in MRPK as a function of TFPR shocks between $t$ and $t-1$. Table 5 lists the estimates for $\gamma_{1}$ by country. In every case, in every specification, we observe a significant, positive coefficient on the capital coefficient, $\gamma_{1}$, as predicted.

A further prediction of our framework is that a producer's MRPK should be mean reverting. We run a regression of MRPK at time $t$ on MPRK at time $t-1$ and obtain estimates of the AR(1) coefficient. This coefficient varies by country from 0.73 for Romania to 0.90 for Chile. The coefficient is significant at the 1 percent level in all cases. Hence, across all countries we find evidence for mean reversion in the MRPK. That is, in the long run, the restriction of adjustment costs on capital fades, and a firm's capital level reverts to the time-invariant mean. ${ }^{23}$

${ }^{23}$ We run $\mathrm{MRPK}_{i t}=\mu+\rho \mathrm{MRPK}_{i t-1}+\nu_{i t}$ by country and include year and industry fixed effects. The standard errors are clustered at the firm/plant level to account for serial correlation and heteroskedasticity. All estimates of $\rho$ are significant at the 1 percent level. Table D.14 in the online appendix lists the estimates. 
2. Aggregate Implications

In addition to the aggregate implication that the dispersion in MRPK is strongly related to the volatility of TFPR, our model suggests two additional aggregate implications: The following moments, at the industryyear level, are all correlated with volatility: $(a)$ the dispersion in the change in MRPK and $(b)$ the dispersion in the change in capital. ${ }^{24}$ We pool across all our tier 1 countries and run reduced-form regressions for both these aggregate variables, measured at the industry-year-country level, on volatility. We include year and country fixed effects and cluster standard errors by country. The regression results are shown in table 6 .

We begin with the dispersion in the change in MRPK, $\mathrm{SD}_{s t}(\Delta \mathrm{MRPK})$. Model simulations (as described in Sec. II.D) indicate that the dispersion in the change in MRPK should be positively correlated with volatility. ${ }^{25}$ In table 6 , we observe a positive and significant correlation between volatility and the dispersion in the change in MRPK both within the US data and within the pooled data across all tier 1 countries (both excluding and including the United States). While the degree of correlation should vary with the persistence of the $\mathrm{AR}(1)$ process present in each country, the positive correlation in the pooled sample is consistent with the model prediction.

The second moment we examine, the dispersion in the change in capital $\mathrm{SD}_{s t}(\Delta k)$, has a strongly nonlinear relationship to volatility. Figure 3 shows the relationship predicted by the model using the same simulation procedure as in Section II, where panel $A$ presents this relationship for the adjustment costs we will estimate for the United States in the next section, and panel $B$ also includes the case without any adjustment cost, but preserving the assumption of a one-period time to build. The reader should note the difference in the vertical scale for these two panels.

Figure 3 reflects the mechanism described in Section II.D. That is, the flattening of the change in capital adjustments as volatility increases reflects the changing trade-off between the size of shocks experienced today and the likelihood that they will be swamped by future shocks. This holds for both panels $A$ and $B$ in figure 3 .

To examine this in a reduced form, we interact the volatility coefficient with a dummy if the volatility associated with that industry-year-country observation is higher than the median for that industry-country. The

${ }^{24}$ A related literature explores the responsiveness of productivity dispersion to the business cycle. Kehrig (2011), Bachmann and Moscarini (2012), and Bloom et al. (2012) all find that productivity volatility increases in recessions. We find no economically significant impact of recessions on the dispersion of MRPK, although, like Bloom et al., we see sales volatility increase. Given that MRPK is the sales to capital ratio, this suggests that capital input adjustments offset any effect coming via changes in sales. See fig. D.2 in the online appendix.

${ }_{25}^{25}$ See fig. D.1 in the online appendix. The line describing the relationship is essentially straight. 
TABLE 6

AgGREGATE IMPLications

\begin{tabular}{|c|c|c|c|}
\hline Aggregate Moment & Coefficient & $R^{2}$ & Observations \\
\hline \multicolumn{4}{|l|}{$\mathrm{SD}_{s t}(\Delta \mathrm{MRPK}):$} \\
\hline United States only & $\begin{array}{l}1.03^{* * * *} \\
.03)\end{array}$ & .63 & 4,039 \\
\hline Excluding the United States & $\begin{array}{l}.56^{* * * *} \\
(.07)\end{array}$ & .64 & 1,289 \\
\hline All countries & $\begin{array}{l}.89^{* * * *} \\
(.04)\end{array}$ & .68 & 5,326 \\
\hline \multicolumn{4}{|l|}{$\operatorname{SD}_{s t}(\Delta k):$} \\
\hline United States only & $\begin{array}{l}.13 * * * \\
(.02)\end{array}$ & .31 & 4,037 \\
\hline Excluding the United States & $\begin{array}{l}.07 * * * \\
(.02)\end{array}$ & .62 & 1,182 \\
\hline All countries & $\begin{array}{l}.12^{* * *} \\
(.02)\end{array}$ & .76 & 5,219 \\
\hline \multicolumn{4}{|l|}{$\operatorname{SD} s t(\Delta k):$} \\
\hline $\begin{array}{l}\text { United States only } \\
\times\{>\text { median vol. }\}\end{array}$ & $\begin{array}{l}.17 * * * \\
(.03) \\
-.03 * * \\
(.01)\end{array}$ & .31 & 4,037 \\
\hline $\begin{array}{l}\text { Excluding the United States } \\
\quad \times\{>\text { median vol. }\}\end{array}$ & $\begin{array}{l}.19 * * \\
(.09) \\
-.09 \\
(.06)\end{array}$ & .63 & 1,182 \\
\hline $\begin{array}{l}\text { All countries } \\
\qquad \times\{>\text { median vol. }\}\end{array}$ & $\begin{array}{l}.17 * * * \\
(.03) \\
-.04 * * \\
(.02)\end{array}$ & .76 & 5,219 \\
\hline
\end{tabular}

NoтE.-The coefficients are obtained by regressing each aggregate moment against volatility using country-industry-year variation, where we include year and country fixed effects. Standard errors (in parentheses) are clustered by country when pooled and by industry when using US data.

** Significant at the 5 percent level.

*** Significant at the 1 percent level.

model prediction is that the coefficient on this interaction is (weakly) negative. As can be seen in table 6 , this coefficient is always negative and, in the case of the United States and the all-country sample, significant.

\section{Adjustment Costs in Other Inputs}

Our model makes the stark assumption that capital is the only input that faces adjustment costs, and our empirical approach builds on this assumption. This is clearly a simplification of the data-generating process.

This approach is based on the implicit claim that, across the span of countries and industries examined in this paper, capital adjustment costs are first order as compared to the adjustment costs of other inputs. A simple way to evaluate this claim is to examine the $(\log )$ dispersion in the marginal revenue products of capital, labor, and intermediate inputs $(k, l$, 

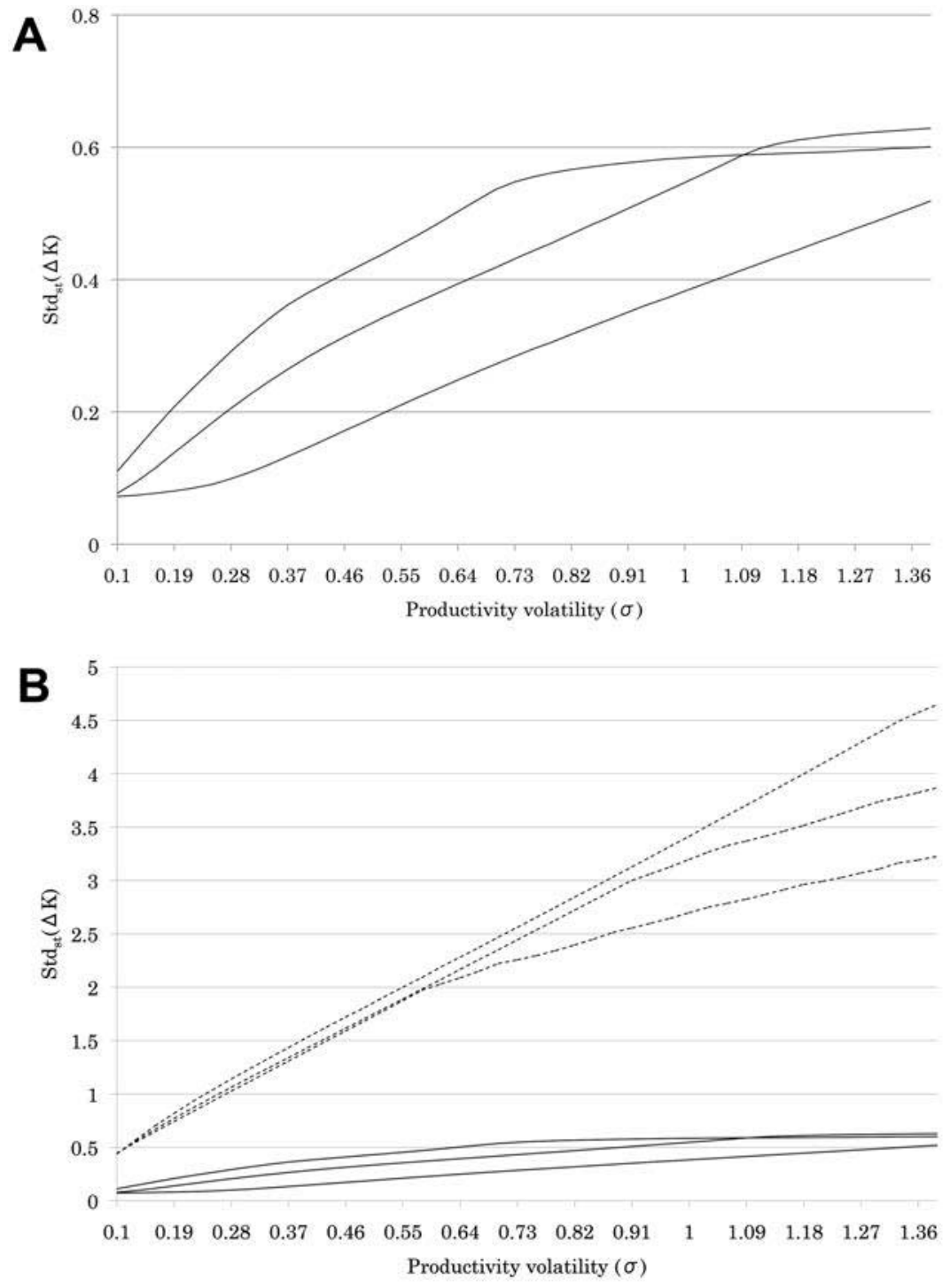

FIG. 3.-Model simulation: dispersion in the change in capital and volatility. Parameters are as for figure 1: $\rho \in\{0.65,0.85,0.94\}$ (corresponding to the lines from bottom $[0.65]$ to top $[0.94]$ when $\sigma=0.3)$.

and $m)$. To do this we compute $\mathrm{SD}_{s t}\left[\ln \left(\beta_{X}\right)+s_{i t}-X_{i t}\right]$ for $X \in\{k, l, m\}$ for each country. Table 7 shows the results.

Across all countries, dispersion in the marginal revenue product of capital is greater than that for any other input. Further, the order of dispersion is overwhelmingly in line with what one might expect: $\mathrm{SD}(\mathrm{MRPK})>$ 
TABLE 7

COMPARING DisPERSION OF MRPK TO OTHER

Inputs' Marginal Revenue Products

\begin{tabular}{lccc}
\hline \hline & \multicolumn{3}{c}{ InPUT } \\
\cline { 2 - 4 } CounTRY & Capital & Labor & Materials \\
\hline United States & .81 & .63 & .54 \\
Chile & 1.22 & .93 & .48 \\
France & 1.25 & .79 & .87 \\
India & 1.01 & .87 & .55 \\
Mexico & 1.19 & .85 & .51 \\
Romania & 1.40 & 1.17 & .67 \\
Slovenia & 1.54 & .98 & .54 \\
Spain & 1.45 & .93 & .70 \\
\hline
\end{tabular}

Note.-We compute the standard deviation of the marginal revenue product of each input by industry-year, and we report the average across industry-years by country.

$\mathrm{SD}(\mathrm{MRPL})>\mathrm{SD}(\mathrm{MRPM}) .{ }^{26}$ Given these results, we proceed with the maintained assumption that capital adjustment costs are the most important component of the adjustment costs likely facing many firms in making input decisions. ${ }^{27}$

\section{Structural Analysis}

In this section we evaluate the ability of the model to capture the magnitude of the degree of dispersion in the marginal product of capital at the industry level across our tier 1 country data sets. We begin by evaluating a baseline specification of our model in which we assume that all industry-countries have the same production technology and the same adjustment costs (we use the US mean production coefficients, with the adjustment costs estimated from the US data). In this simple version, the only thing that varies over industries in the structural model is the AR(1) process governing TFPR shocks. This specification is intended to highlight

${ }^{26}$ Moreover, we also find that the relationship of dispersion in MRPK and volatility holds up in every data set (including tier 1 and tier 2), while for the MPRL and MRPM, this is far from the case. In fact, we could not find any particular pattern (either a positive or negative relationship) across all countries between volatility and the dispersion measures for $L$ and M. Table D.18 in the online appendix lists these estimates.

${ }^{27}$ Bloom et al. (2012) estimate a structural model of adjustment costs in both labor and capital using Compustat data on US firms. While the model of Bloom (2009) is suggestive of a similar extension in our setting, given that we encompass eight countries in our tier 1 data and 33 in our tier 2 data set, we have chosen to use a more parsimonious model. In our data environment, it seems to strike an appropriate balance between realism, insight, and feasibility. 
the extent to which, on its own, the TFPR shock process can capture dispersion in marginal products.

Following this baseline specification, we explore the extent to which using industry-specific production functions and different adjustment cost specifications allows us to capture additional richness. Before getting to these results, we first set out the elements in the structural estimation of the model.

\section{A. Estimation}

We briefly discuss the estimation of the crucial parameters of our structural model, those that vary by industry - that is, the TFPR process - and how we recover the estimates of the adjustment cost parameters.

The AR(1) TFPR process is specified as $\omega_{i t}=\mu_{s c}+\rho_{s c} \omega_{i t-1}+\sigma_{s c} \nu_{i t}$. Note that the coefficients are country-industry specific. Estimation follows the procedure described in Section IV and relies on standard maximum likelihood estimation techniques to recover the parameters.

Recall that the adjustment cost specification is given by

$$
C\left(I_{i t}, K_{i t}, \Omega_{i t}\right)=I_{i t}+C_{K}^{F} \mathbf{1}(\cdot)\left\{I_{i t} \neq 0\right\} \pi\left(\Omega_{i t}, K_{i t}\right)+C_{K}^{Q} K_{i t}\left(\frac{I_{i t}}{K_{i t}}\right)^{2} .
$$

We estimate $\theta=\left\{C_{K}^{F}, C_{K}^{Q}\right\}$ using a minimum-distance procedure very similar to that in Cooper and Haltiwanger (2006). That is, we seek parameters that minimize the distance between the moments predicted by the model and those that are found in the data. The moments we use are the proportion of firms with less than a 5 percent year-on-year change in capital, the proportion of firms with more than a 20 percent year-on-year change in capital, and the standard deviation of the year-on-year change in log capital. ${ }^{28}$

Denote the predicted moments from the model for an industry $s$ in country $c$ as $\Psi_{c s}(\theta)$, found by solving for the firms' optimal policies and simulating the model forward for 1,000 months for 10,000 firms, and computing moments based on the last 2 years of the simulated data set. ${ }^{29}$ These predictions may differ across industries, depending on production

${ }^{28}$ Notice that according to the results of theorem 1, stated in App. A, these moments are invariant to differences in the mean $\mu$ of the TFPR process, and thus we do not need to take a stand on the presence of a firm fixed effect in the estimation procedure. However, we have also looked at the model's predictions using estimates of the AR(1) process that include a producer fixed effect for the United States, and we find comparable results (contained in table D.3 in the online appendix).

${ }^{29}$ We employ a very fine grid for capital stock (of 3 percent), since fixed costs are identified from the absence of small changes in capital. With a coarser grid for capital stock, it is difficult to identify small fixed costs. This comes at the expense of computational time, and solving the 
function coefficients $\beta_{l}, \beta_{m}$, and $\beta_{k}$, as well as the TFPR process estimated in the previous subsection. We then aggregate the industry prediction to the country level by taking a weighted average of the industry-level prediction, that is,

$$
\Psi_{c}(\theta)=\frac{1}{\sum_{s} N_{s c}} \sum_{s} N_{s c} \Psi_{c s}(\theta)
$$

where $N_{s c}$ denotes the number of producers in industry $s$ for country $c$. Thus, the country-level predictions are matched to country-level moments on changes in capital, where the moments from the data are denoted $\hat{\Psi}$.

We estimate the model's adjustment costs using minimum distance with a criterion function given by the usual quadratic form, with weighting matrix $\mathbf{W}$ :

$$
\mathcal{Q}(\theta)=(\hat{\Psi}-\Psi(\theta))^{\prime} \mathbf{W}(\hat{\Psi}-\Psi(\theta)) .
$$

As the moments in the data are similarly scaled, we pick the identity matrix as a weighting matrix $(\mathbf{W}=\mathbf{I})$. We find the minimized value of the criterion using a grid search.

Table 8 presents estimates of the adjustment costs by country, along with the moments used to estimate the model. Three aspects of the table are noteworthy.

First, the moments on the year-to-year change in capital differ substantially between countries. For the United States, over 39 percent of plants do not change their capital by more than 5 percent, while this number is 20 percent for Spain and 8 percent for Romania. ${ }^{30}$ Likewise, the share of plants that vary their capital by more than 20 percent is 9 percent for the United States, 73 percent for Mexico, but 52 percent for Slovenia. These differences in the variation of capital translate into differences in the estimated adjustment costs by country, with the United States having relatively high convex and fixed adjustment costs and Mexico having convex adjustment costs that are at least one-fifth of those of the United States.

The large differences in moments on changes in capital are striking. Beyond differences in adjustment costs, they also reflect differences in patterns of aggregate growth for each of these countries and differences in the data collection protocols for tier 1 data. For instance, Slovenia experienced a rapid increase in output over the time period we study (19942000), but this is not the case for the US manufacturing sector from 1972

value function takes over a half hour. The total computation time required for a single 3gigahertz processor to complete the estimation and simulations reported in this section is 2,286,000 minutes (1,587 days). The computational burden was significantly reduced via parallel computation on a large computing cluster at New York University. For further details regarding computation, see App. C.

${ }_{30}$ Note that data for Spain and Romania are at the firm level. 
TABLE 8

Adjustment Cost Estimates and Moments by Country

\begin{tabular}{|c|c|c|c|c|c|}
\hline \multirow[b]{2}{*}{ COUnTRY } & \multicolumn{2}{|c|}{$\begin{array}{l}\text { Adjustment } \\
\text { Costs }\end{array}$} & \multicolumn{3}{|c|}{ Data Moments on Change in log Capital } \\
\hline & Convex & Fixed & Less than $5 \%$ & More than $20 \%$ & $\begin{array}{l}\text { Standard } \\
\text { Deviation }\end{array}$ \\
\hline United States & 8.80 & .09 & .39 & .09 & .21 \\
\hline Chile & 4.10 & .07 & .19 & .11 & .28 \\
\hline India & 3.46 & .12 & .29 & .19 & .30 \\
\hline France & .21 & .00 & .13 & .57 & .57 \\
\hline Spain & .74 & .00 & .20 & .41 & .59 \\
\hline Mexico & 1.15 & .22 & .08 & .73 & .66 \\
\hline Romania & .66 & .03 & .08 & .61 & .72 \\
\hline Slovenia & .35 & .00 & .15 & .52 & .76 \\
\hline
\end{tabular}

NoTE.-Standard errors were computed using the usual formula for minimum-distance estimators. However, because of the large size of the data sets we employ, the standard errors are of the order of $1 \times 10^{-3}$ or smaller, and so we do not report them. Adjustment costs for Slovenia are based on a model with production function coefficients set to the mean US coefficients (see the discussion in Sec. V.B).

to $1997 .{ }^{31}$ Also, for some data sets, changes in capital are computed from the change in the reported book value of assets, while for other data sets, these are inferred from investment and depreciation. Presumably, these differences in the reporting protocol will also lead to differences in the measurement in the change in capital.

Second, for several countries-France, Mexico, and Romania-we estimate no fixed costs of adjustment (beyond the one-period time to build, which is in itself a form of adjustment friction). In these countries, even with no fixed cost of adjustment, the model predicts that fewer firms would change their capital by less than 5 percent than what we find in the data. Conversely, a zero convex cost of adjustment is strongly rejected. As the convex adjustment costs get closer to zero, the volatility of capital rises sharply. Given the data, this allows us to conclusively reject the absence of any costs of adjusting a firm's capital stock.

Third, focusing on the United States, we obtain the following estimates: fixed adjustment costs $\left(C_{K}^{F}\right), 0.09$; and convex adjustment cost $\left(C_{K}^{Q}\right), 8.8$. The fixed cost of adjustment is equivalent to 1.5 months of output, while the convex adjustment costs are such that when a firm doubles its capital in a month, this component of cost is equal to 8.8 times the value of its investment. ${ }^{32}$

${ }^{31}$ Since the standard approach to estimating adjustment costs we use, such as found in Cooper and Haltiwanger (2006) or Bloom (2009), matches moments from the steady-state distribution, this type of model has difficulty dealing with aggregate shocks.

${ }^{32}$ These parameters can be compared to those found in Bloom (2009, table 3, col. 2). Using a sample of (only) large publicly listed firms in Compustat, they obtain fixed adjustment costs of 0.01 and convex adjustment costs of 1.00. 
To assess the fit of the model, we compute the sum of squared errors, scaled by the sum of the squared "dependent" variable (data). That is, if the data are a vector $\mathbf{x}$ that is predicted by a variable $\hat{\mathbf{x}}$, then we compute

$$
S^{2}=1-\frac{(\mathbf{x}-\hat{\mathbf{x}})^{\prime}(\mathbf{x}-\hat{\mathbf{x}})}{\mathbf{x}^{\prime} \mathbf{x}}
$$

as our measure of fit. This measure of fit is closely related to the uncentered $R^{2}$ measure of fit familiar from regression analysis. However, because our model's prediction does not come from a regression, but from a parameterized model, nothing in the structure restricts $S^{2}$ to lie in $[0,1]$, though, by definition, it must be less than or equal to one. That being said, to map our measure of fit into a context equivalent to the $R^{2}$, it is correct to interpret $S^{2}$ as the proportion of the observed data captured by the model's prediction, with the caveat that it is possible for this number to be negative.

\section{B. Results}

As noted above, our baseline specification assumes that all industries in all countries have the same adjustment costs and the same production technology. We take both from the US data: we use the mean US production coefficients and US adjustment costs. ${ }^{33}$ Our objective in evaluating this specification is to highlight the extent to which (just) differences in the $\mathrm{AR}(1)$ process can capture dispersion in the marginal revenue product of capital, at the industry level, across a variety of data sets (equivalently, countries).

Table 9 shows the $S^{2}$ measure of fit, comparing the model prediction of the dispersion in the MRPK to that observed in our various tier 1 data sets. When we pool across all industry-countries, the $S^{2}$ is 0.674 , while if the United States is excluded, the $S^{2}$ is 0.879 . This suggests that the model does a good job of capturing the observed dispersion. It also highlights the curious fact that the performance of this baseline model is worst on the US data, despite being based on US numbers.

The US $S^{2}$ is 0.223 , as compared to 0.879 for all non-US countries. The reason for this is that the US data employ a far finer industry definition than our other data sets. In the US data, firms are allocated to one of 188 industry classifications, whereas in the other data the number of industries varies from eight (Chile) to 52 (Mexico). ${ }^{34}$ This means that, when

\footnotetext{
${ }^{33}$ Mean production coefficients are computed by taking the mean of the industry labor and materials coefficients and then using these to compute the capital coefficient.

${ }^{34}$ After we account for disclosure and basic data integrity (i.e., missing data, etc.), the numbers of industries by country (data set) are as follows: Chile, 8; France, 21; India, 20; Mexico, 52; Romania, 21; Slovenia, 18; and Spain, 22. The United States has 188. This
} 
TABLE 9

Dispersion IN MRPK, $S^{2}$ Measures of Model Fit by Specification

\begin{tabular}{|c|c|c|c|c|c|}
\hline \multirow[b]{2}{*}{ COUntry } & \multicolumn{5}{|c|}{ SPECIFICATION } \\
\hline & $(1)$ & (2) & $(3)$ & (4) & (5) \\
\hline United States & .223 & .806 & .806 & .643 & .820 \\
\hline France & .892 & .702 & .899 & .944 & .651 \\
\hline Chile & .994 & .983 & .987 & .963 & .785 \\
\hline India & .984 & .941 & .964 & .976 & .596 \\
\hline Mexico & .879 & .813 & .883 & .908 & .634 \\
\hline Romania & .983 & .923 & .817 & .702 & .846 \\
\hline Slovenia & .967 & .774 & .967 & .984 & .683 \\
\hline Spain & .718 & .627 & .600 & .530 & .495 \\
\hline All (excluding United States) & .879 & .777 & .820 & .800 & .640 \\
\hline All & .674 & .786 & .816 & .748 & .696 \\
\hline \multicolumn{6}{|l|}{ Specification details: } \\
\hline All US adjusted costs & $\mathrm{X}$ & & $\mathrm{X}$ & & \\
\hline Own-country adjusted costs & & $\mathrm{X}$ & & & \\
\hline All $2 \times$ US adjusted costs & & & & $\mathrm{X}$ & \\
\hline 1-period time to build only & & & & & $\mathrm{X}$ \\
\hline US average $\beta$ 's & $\mathrm{X}$ & & & & \\
\hline Industry-country $\beta$ 's & & $\mathrm{X}$ & $\mathrm{X}$ & $\mathrm{X}$ & $\mathrm{X}$ \\
\hline
\end{tabular}

Note.-The unit of observation is the country-industry. Specifications are as follows: (1) All countries have the United States' estimated adjustment costs and production coefficients equal to the US averages across industries; (2) industry-country-specific production coefficients (except for Slovenia; see Sec. III.B), country specific adjustment costs, and industry-country-specific $\operatorname{AR}(1)$; (3) same as for 2, but with the United States' estimated adjustment costs for all countries; (4) same as for 3, but with twice the United States'estimated adjustment costs for all countries; and (5) same as for 3, but with zero adjustment costs (other than the one-period time to build) for all countries. In all specifications, the $\mathrm{AR}(1)$ is estimated using TFPR computed using the production coefficients used in the model specification.

we impose mean production coefficients, we do so on industry definitions that incorporate differing levels of aggregation. In the United States, where the industries are finely defined, this means that some industries will have firms that all use production technologies that differ markedly from the standard firm in the economy. As a result, the baseline model can have a hard time capturing the investment patterns observed in these industries when it has to use the production coefficients from a "standard" firm.

The impact of industry heterogeneity in the US data is illustrated by comparing specification 2 to specification 1 for the United States. ${ }^{35}$ Specification 2 adds industry-specific production coefficients to the model. Once industries are allowed to vary in their production technology, the

merely reflects that the detail of industrial activity reporting varies across data sets. For example, for the French data we observe the principal activity of the firm, a two-digit industry code, while we also observe its (potentially) multiple four-digit industry codes. However, we do not see the output and input data broken down at this level of aggregation, which is standard in these data.

${ }^{35}$ In table 9, specifications 2 and 3 are equivalent for the United States. 
US $S^{2}$ increases from 0.223 to 0.806 , reflecting the model's increased capacity to capture investment patterns across a much wider range of industries.

As illustrated by the preceding discussion of the baseline results, adding more flexibility to the model can increase the extent to which the dispersion in the data can be captured. To this end, we depart from the baseline model and allow each country to have its own adjustment costs (from table 8 ) and allow each country-industry to have its own production function coefficients (specification 2 in table 9). Following that, we investigate the sensitivity of this expanded model to changes in the adjustment costs: we impose US adjustment costs, twice the US adjustment costs, and zero adjustment costs (aside from the one-period time to build) on all countries (specifications 3, 4, and 5, respectively, in table 9).

Prior to discussing results, we outline some measurement issues: Recall that we assume $\beta_{l}+\beta_{m}+\beta_{k}=0.75$ (given constant returns in the production function and a demand elasticity of -4 ). Given this, we handle the data as described in Section III.B with one exception: In the Slovenian data, the material coefficient is greater than 0.75 on average. As a result, a strict application of our procedure would imply negative capital coefficients for all Slovenian manufacturing sectors, which we think is not plausible. To avoid having to omit Slovenia, an interesting country in its own right, we use the mean US coefficients to generate all Slovenian results in this section. ${ }^{36}$

Across specifications 2, 3, 4, and 5, there is little qualitative difference in the capacity for the model to capture dispersion. This reflects the good fit of the baseline model. That is, there is not a great deal of scope for improvement in many cases. Perhaps most interestingly, the model's performance in capturing dispersion in MRPK is not dramatically altered by changing the level of adjustment costs. A zero adjustment cost reduces fit in most countries somewhat, but imposing twice the US adjustment cost does not have an economically meaningful impact. This suggests that the presence of some capital adjustment friction is important but that the extent of the friction is not crucial, at least as far as dispersion in MRPK is concerned. ${ }^{37}$ In the absence of any adjustment

\footnotetext{
${ }^{36}$ Slovenia is interesting because of the volatility introduced by the transition process it experienced during our sample time period. Using US production coefficients keeps the specification consistent with the structural model, albeit in a way that restricts us to examining how Slovenian firms would behave if they had the production technology of US firms.

${ }^{37}$ For other moments, notably the dispersion in the change in capital, the level of the adjustment can make a significant difference. See table D.2 in the online appendix and, in particular, col. 5 corresponding to the case of no adjustment costs. To examine the sensitivity of the models' predictions to the potential misspecification of the productivity process, we leverage theorem 1 and impose the $\sigma$ and $\rho$ terms from an alternative productivity process allowing for firm fixed effects, where we rely on various dynamic panel data estimators. Table D.3 shows that our results are robust to the inclusion of producer-level fixed effects in the productivity process.
} 
cost in capital, including time to build, the model evaluated under our parameter values an $S^{2}$ of zero (underprediction). Note that, when the model overpredicts dispersion, it is possible for this $S^{2}$ measure to become negative.

\section{Cross-Country Analysis}

The main source of variation that we have relied on thus far is crossindustry variation within a country. Although our results suggest a positive correlation between dispersion and volatility in cross-country settings, drawing a stronger inference is limited by having a sample of only eight countries, each with different data collection protocols. In this section, in order to provide auxiliary evidence that speaks to such a conclusion, we exploit a larger cross section of developing countries for which we observe a sample of firms for only, at most, three consecutive periods. To this end, we rely on the WBES data. These data trade off greater cross-country variation at the expense of stricter data collection protocols and a much larger, within-country, sample of firms. As before, we apply our reducedform and structural analysis (as carried out in Secs. IV and V, respectively) on a large cross section of countries. We briefly introduce the data before we present our results.

\section{A. The WBES Data}

The WBES data were collected by the World Bank across 41 developing countries and many different industries between 2002 and 2006. Standard output and input measures are reported in a harmonized fashion. In particular, the data report sales, intermediate inputs, various measures of capital, and employment for a 3-year period, which allows us to compute changes in TFPR and capital. Out of the 41 countries in the data, 33 have usable firm-level observations. The reason is primarily that for many years and countries, the World Bank did not collect multiyear data on capital stock.

To construct data on both TFPR and the change in TFPR, we need two years of information on sales, assets, intermediate inputs, and employment; 5,558 firms across our 33 countries meet this criterion. ${ }^{38}$ The firms in the final data are almost certainly not representative of firms in their economies; for instance, the mean number of workers is 248. Thus, for instance, the data tend to oversample larger firms. In Appendix B we provide further details on sample construction and compare the firms in our sample with the universe of sampled firms.

\footnotetext{
${ }^{38}$ We also drop countries with fewer than 25 observations.
} 
B. Cross-Country Reduced-Form Results

We start by establishing the relationship between static misallocation and volatility across countries, using a method similar to what we used at the industry level. Figure $4 B$ plots the volatility of TFPR against the dispersion of MRPK for our 33 countries in the WBES data. We find the same striking positive relationship as we presented in figure 2 in Section IV using US census data. Figure $4 A$ shows the same exercise for the eight tier 1 countries.

The solid black line in panel $B$ shows the line of best fit, corresponding to a regression in which dispersion is projected onto a constant and volatility, where country observations are weighted by the number of incountry observations. ${ }^{39}$ This positive, significant, correlation between dispersion and volatility is robust to specifications that use alternative weights, industry fixed effects, and controls for firm size. ${ }^{40}$ The relationship can also be replicated using country-industry observations.

\section{Structural Analysis}

We now perform a structural analysis of the World Bank data, in the same spirit as that conducted in Section V. We apply the same model, with two alterations. We estimate an $\mathrm{AR}(1)$ process for TFPR at the country level, and we use the adjustment costs estimated for the United States reported in table 8 . We use US adjustment costs since we found in the analysis of the tier 1 country data sets that the precise level of adjustment costs appears to have little influence on the ability of the model to capture the dispersion in the MRPK. Hence, we examine the capacity of the model to capture dispersion using this simple specification.

To obtain country-level predictions, we aggregate predictions at the industry level, using the number of producers in an industry as weights. Moreover, since dispersion in MRPK at the country level includes variation in MRPK both within an industry and between industries, we need to account for both these sources of variation when aggregating MRPK.

The results are depicted in figure 5. The countries in the World Bank data are shown using unfilled circles, while, for comparison, the tier 1 countries are shown using filled circles. ${ }^{41}$ The horizontal axis measures the model's prediction, while the vertical axis measures the dispersion in MRPK present in the data.

${ }^{39}$ See the notes accompanying the figure for the coefficients and standard errors.

${ }^{40}$ The last two specifications use firm-level observations. A complete set of results can be found in table D.16 in the online appendix.

${ }^{41}$ The tier 1 country data are aggregated in the same way as the World Bank data, and we use a country-specific $\mathrm{AR}(1)$ process in the model simulation. 

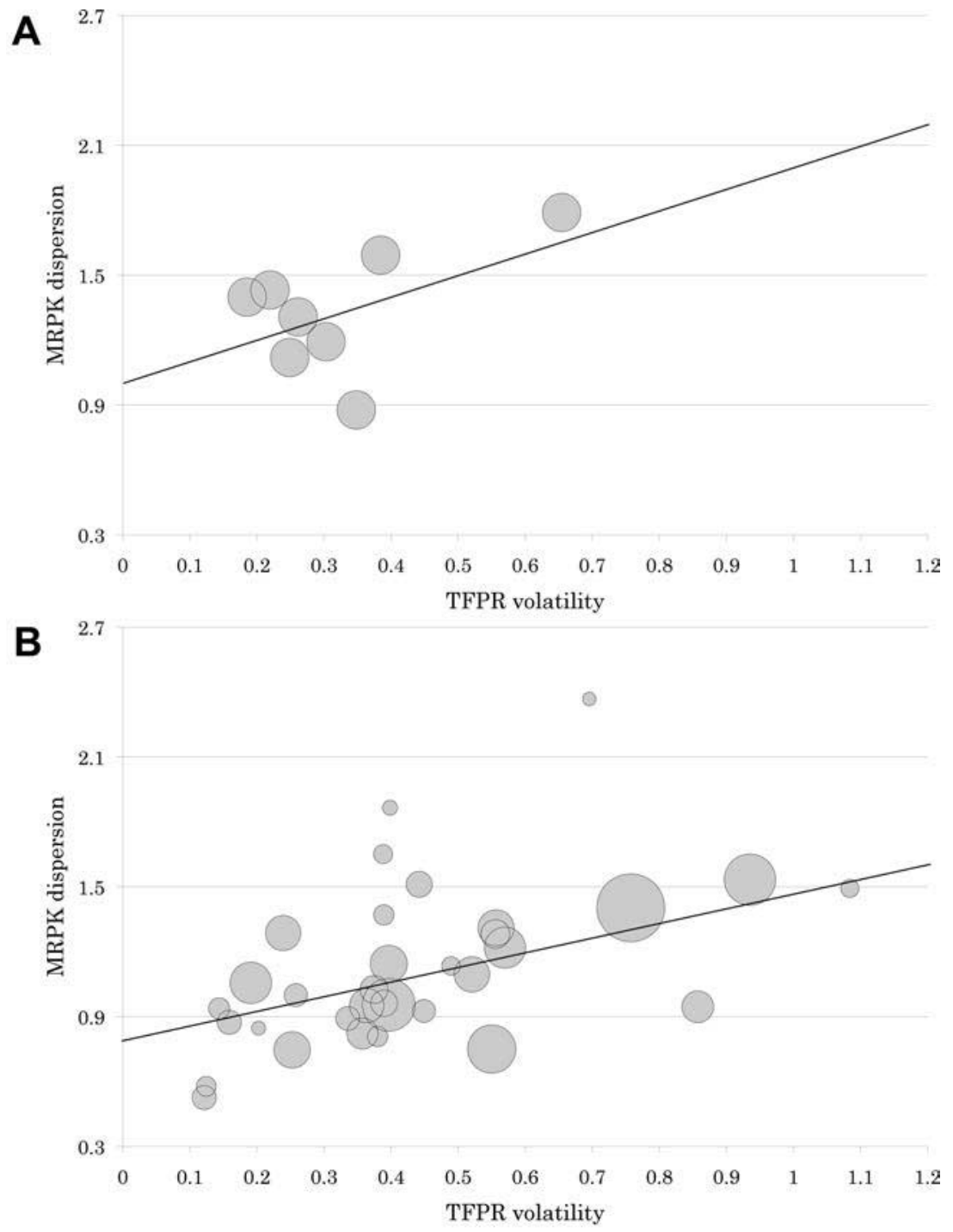

FIG. 4.-Country-level static misallocation and TFPR volatility. Circles indicate countries, where circle size for tier 2 data (panel $B$ ) is increasing in the number of firms per country. The bold straight line is the line of best fit (computed using OLS with a constant term). The horizontal axis indicates the value of the standard deviation of $\omega_{i t}-\omega_{i t-1}$. The vertical axis indicates the standard deviation in MRPK. The regression line for panel $A$ is given by 1.01 $(0.23)+1.02(0.66) \times \mathrm{vol}$ with an $R^{2}$ of .28 . The regression line for panel $B$ is given by 0.78 $(0.10)+0.67(0.21) \times$ vol with an $R^{2}$ of .31 , where standard errors are given in parentheses, and vol denotes our measure of volatility. 


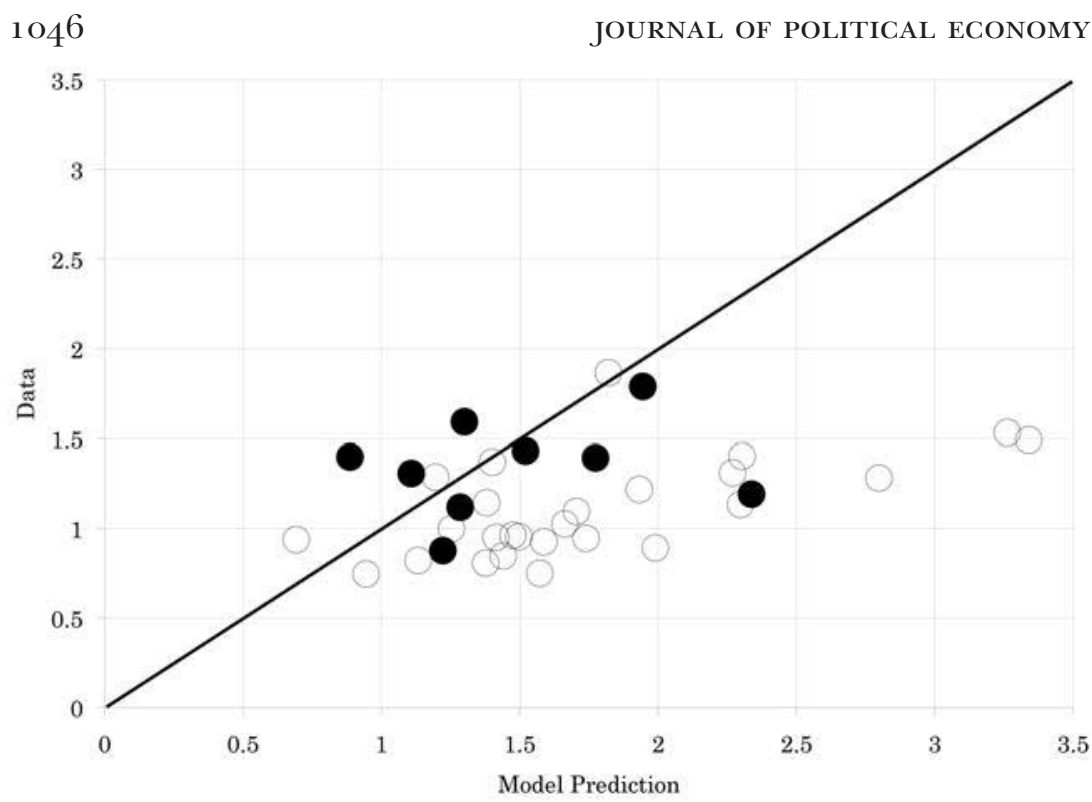

FIG. 5.-Country-level MRPK dispersion: data versus model simulation. The vertical axis is data, while the horizontal axis is the model prediction. The unit of observation is the country. Predictions are computed at the industry-country level and then aggregated to the country level. Black dots are tier 1 countries. Unfilled circles are countries in the WBES data. All predictions use industry-country-specific production coefficients, a country-level $\mathrm{AR}(1)$ process, and the adjustment costs estimated for the United States in Section V. The $S^{2}$ for the World Bank countries is 0.802 and is 0.906 for the tier 1 countries. The solid line is the 45-degree line.

The model does quite well. The $S^{2}$ for the WBES countries is 0.802 . This is comparable to the model performance reported in table 9 for the industry-level data from tier 1 countries. When we treat the tier 1 country data in the same way as the WBES data, we get an $S^{2}$ of 0.906 . Also, if anything, the model has a tendency to overpredict the dispersion in MRPK, suggesting that the dispersion observed in data is less than what might be expected to be generated by firms operating in the United States, facing US adjustment costs, but otherwise equivalent $\operatorname{AR}(1)$ and technological environments.

\section{Volatility and External Measures}

So far, our strategy has been to estimate volatility of TFPR and see how this measure of volatility is linked to the dispersion in various economic variables. We have shown that volatility varies across industries within countries as well as across countries. Although it is beyond the scope of this paper to develop a theory of volatility to explain why volatility varies 
across different economic environments, it is only natural to ask whether our measures of differences in volatility across countries are related to features of these economies.

To this end we match the World Bank Doing Business Dataset (henceforth the WBDB data) with the WBES data and check whether volatility is correlated with some of the survey questions in the WBDB data. In particular, we examine whether countries with greater volatility also face more frictions in contract enforcement-measured in terms of cost and duration of contract enforcement-factors that would plausibly affect the uncertainty faced by producers. Similarly, we also collected data on the extent of natural disasters per unit of landmass and an index of political stability. ${ }^{42}$

When we regress volatility against the cost of contract enforcement measure, the duration measure, and a constant, we find a significant - at the 10 percent level - and positive coefficient on cost and an $R^{2}$ of 7 percent. Time to enforce is not significant, economically or statistically. This suggests that countries that exhibit larger volatility are also characterized by higher contracting costs. A regression of volatility on a constant and natural disasters per unit of landmass also yields a positive coefficient on political stability and is also significant at the 10 percent level. Given the limited number of countries for which we have measures of volatility, this seems as precise an estimate as one could reasonably expect. Interestingly, the political stability index is not significant in any regression, although the correlation does have a negative sign. When we run a regression with all our measures of the economic environment in a country against volatility, we find, as before, that the cost of contract enforcement is associated with significantly higher volatility. Moreover, the $F$-statistic is significant at the 10 percent level, indicating that the combination of cost and duration of contract enforcement, political instability, and natural disasters does explain some component of the cross-country differences we observe in volatility. In particular, this simple linear cross-sectional regression leads to an $R^{2}$ of 14.3 percent. While speculative, these reported correlations suggest that there may be linkages between volatility and features of a country's operating environment that are worth investigating further.

\section{Conclusion}

The primary contribution of this paper is to establish the link between the dynamic process governing TFPR changes over time and cross-sectional

${ }^{42}$ The online appendix provides more details on the data and the analysis: sec. D.1 describes the data and variable construction. Table D.13 presents the regression results. 
measures of dispersion in the marginal product of capital. We have shown that a parsimonious model of the TFPR process coupled with capital adjustment costs explains both the level and variation of the dispersion in the static marginal revenue product of capital across industries within countries and across countries. We do this by examining eight large-scale country-level data sets, including the US census (tier 1 data), and then extend the analysis with data from the World Bank on a further 33 developing countries (tier 2 data). The cross-industry findings are primarily supported by the tier 1 data, while the cross-country findings are primarily supported by the tier 2 data.

These findings suggest that producers in industries (countries) that experience larger "uncertainty" in the future operating environment (i.e., higher volatility in TFPR) make investment decisions different from those of producers active in less volatile environments. This leads to different levels of capital and output and, moreover, means that the welfare gains from policies inducing reallocation of factors of production are likely to be lower than otherwise implied by static models, at least to the extent that the TFPR process is exogenous. Indeed, if one has the view that the productivity process is an exogenous, or primitive, feature of the model, then our findings suggest that, in an aggregate sense, the firms in the countries we studied are acting much as the social planner in our model would have them act (assuming that the social planner takes the capital adjustment costs as given). This suggests that there are few welfare implications for differences in cross-sectional measures of (static) capital misallocation across industries or countries. On the other hand, if government policy can affect the productivity process, then there may be significant welfare dividends to policy interventions aimed at moving toward some socially optimal productivity process. However, characterization of what this optimal process is likely requires a more subtle modeling approach than that offered here.

This raises the important issue of the specific sources of adjustment costs and TFPR volatility, a topic on which we provide some suggestive evidence but otherwise leave open for future research. In particular, TFPR is not just technological in nature. Our measure of TFPR volatility will capture changes in managerial and physical technology. It will also capture year-on-year variation in the intensity of corruption (and the implicit tax therein), other aspects of the application of the rule of law relevant to business (such as erratic contract enforceability), changing regulatory frictions, environmental factors (e.g., floods and other natural disasters) and the efficacy of infrastructure used to cope with them, and year-on-year variation in markups and product market competition. Many of these elements of measured productivity volatility may be effectively influenced by appropriate policy aimed at providing a stable business environment. 


\section{Appendix A}

Proof of Invariance to Fixed Effects in Productivity Process

Theorem 1. Consider the dynamic optimization problem described by the Bellman equation

$$
\begin{aligned}
V(\Omega, K)= & \max _{I, M, L} S(\Omega, K, L, M)-p_{L} L-p_{M} M-C(I, K, L, M, \Omega) \\
& +\beta \int_{\Omega^{\prime}} V\left(\Omega^{\prime}, \delta K+I\right) f\left(d \Omega^{\prime} \mid \Omega\right) .
\end{aligned}
$$

Let $f\left(\Omega^{\prime} \mid \Omega\right)$ be described by one of the following processes:

A. $\omega_{i t+1}=\mu_{i}+\rho \omega_{i t}+\sigma \epsilon_{i t}$ and

B. $\tilde{\omega}_{i t+1}=\tilde{\mu}_{i}+\rho \tilde{\omega}_{i t}+\sigma \epsilon_{i t}$.

Then, for any $\mu_{i}$ and $\tilde{\mu}_{i}$,

i. $\left(s_{i t}-x_{i t} \mid \mu_{i}\right)=\left(s_{i t}-x_{i t} \mid \tilde{\mu}_{i}\right)$ and

ii. $\left(x_{i t}-x_{i t-1} \mid \mu_{i}\right)=\left(x_{i t}-x_{i t-1} \mid \tilde{\mu}_{i}\right)$, where $x \in\{l, m, k\}$.

Proof. The proof proceeds by (1) showing that changing the constant in the $\mathrm{AR}(1)$ amounts to a level shift in the $\mathrm{AR}(1)$ process, (2) showing that the entire problem is homogenous of degree one, (3) using this to show that changing the $\mathrm{AR}(1)$ constant results in a level shift in the inputs, and (4) noting that these level shifts get canceled out when computing differences at the firm level. We use a series of lemmas to develop this reasoning. ${ }^{43}$

Lemma 1. Consider two processes $A$ and $B$ above. Process $B$ is a level shift of process $A$. That is, conditional on initial conditions and the history of $\epsilon_{i t}$, $\tilde{\omega}_{i t}=\omega_{i t}+\log \Lambda$, where $(1-\rho) \log \Lambda=\tilde{\mu}_{i}-\mu_{i}$.

Proof. Starting with process $A$, increase $\omega_{i t}$ by $\log \Lambda$. Now, consider the evolution of process $B$ from $\omega_{i t}+\log \Lambda$ :

$$
\begin{aligned}
\tilde{\omega}_{i t+1} & =\tilde{\mu}_{i}+\rho\left(\omega_{i t}+\log \Lambda\right)+\sigma \epsilon_{i t} \\
& =\mu_{i}+(1-\rho) \log \Lambda+\rho\left(\omega_{i t}+\log \Lambda\right)+\sigma \epsilon_{i t} \\
& =\mu_{i}+\log \Lambda+\rho \omega_{i t}+\sigma \epsilon_{i t} \\
& =\omega_{i t+1}+\log \Lambda .
\end{aligned}
$$

Hence, process $B$ is a level shift of process $A$. QED

Lemma 2. A process determining the evolution of $\tilde{\Omega}$, where $\log \tilde{\Omega}=\tilde{\omega}$, described by $B$, is isomorphic, in terms of realizations of random variables, to a process determining $\Lambda \Omega$, where the process describing the evolution of $\Omega$ is $A$.

Proof. This is a corollary of lemma 1. QED

${ }^{43}$ In both the theorem and proof, unless noted otherwise, variable definitions and notation follow those used in the paper. 
The rest of the proof employs a transformation of the problem. ${ }^{44}$ Let

$$
G_{i t}^{1-a-b-c}=\Omega_{i t} \quad \text { and } \quad(1-a-b-c) g_{i t}=\omega_{i t} ;
$$

since this is a bijective mapping, we can rewrite the TFPR process as

$$
(1-a-b-c) g_{i t+1}=\mu_{i}+\rho(1-a-b-c) g_{i t}+\sigma \epsilon_{i t}
$$

and the sales function as

$$
S_{i t}=G_{i t}^{1-a-b-c} K_{i t}^{a} L_{i t}^{b} M_{i t}^{c} .
$$

This transformation will allow us to exploit homogeneity properties in a transparent manner. To keep notation consistent but distinct, let $\lambda^{1-a-b-c}=\Lambda$. Note the following lemma.

Lemma 3 (Sales).

$$
\lambda S_{i t}\left(G_{i t}, K_{i t}, L_{i t}, M_{i t}\right)=S_{i t}\left(\lambda G_{i t}, \lambda K_{i t}, \lambda L_{i t}, \lambda M_{i t}\right) .
$$

Before we proceed to the homogeneity of the value function, it is helpful to establish that the static inputs, $L$ and $M$, under processes $A$ and $B$, are (multiplicative) level shifts of each other. This makes it easier to state subsequent lemmas and manipulate the value function.

Lemma 4. If $L_{i t}^{*}$ and $M_{i t}^{*}$ are solutions to the system of first-order conditions of static inputs, given $G_{i t}$ and $K_{i t}$, then, given $\lambda G_{i t}$ and $\lambda K_{i t}, \lambda L_{i t}^{*}$ and $\lambda M_{i t}^{*}$ are solutions.

Proof. It is sufficient to show that this is true for labor. As established in the paper, the first-order condition is

$$
\frac{b S_{i t}\left(G_{i t}, K_{i t}, L_{i t}^{*}, M_{i t}^{*}\right)}{L_{i t}^{*}}=p_{L} .
$$

Now, we need to show that, given $\lambda G_{i t}$ and $\lambda K_{i t}, \lambda L_{i t}^{*}$ and $\lambda M_{i t}^{*}$ solve the firstorder condition:

$$
\begin{aligned}
\frac{b S_{i t}\left(\lambda G_{i t}, \lambda K_{i t}, \lambda L_{i t}^{*}, \lambda M_{i t}^{*}\right)}{\lambda L_{i t}^{*}} & =\frac{b \lambda S\left(G_{i t}, K_{i t}, L_{i t}^{*}, M_{i t}^{*}\right)}{\lambda L^{*}} \\
& =\frac{b S_{i t}\left(G_{i t}, K_{i t}, L_{i t}^{*}, M_{i t}^{*}\right)}{L^{*}} \\
& =p_{L},
\end{aligned}
$$

where the first equality follows from lemma 3 and the last from equation (A3). Hence, $\lambda L_{i t}^{*}$ and $\lambda M_{i t}^{*}$ solve the first-order condition. QED

Lemma 4 allows us to express everything that follows as functions of $G$ and $K$ (and $I$ ), noting that, where relevant, a proportional increase in both leads to an equivalent proportional increase in $L$ and $M$. Note, in particular, that we can rewrite the Bellman equation as

${ }^{44}$ Bloom (2009) employs a similar transformation (see n. 23). 


$$
\begin{aligned}
V(G, K)= & \max _{I} \pi(G, K)-C(G, K, I) \\
& +\beta \int_{G^{\prime}} V\left(G^{\prime}, \delta K+I\right) \phi\left(d G^{\prime} \mid G\right) .
\end{aligned}
$$

We now turn to establishing the homogeneity properties of the various components of the Bellman equation, stated in theorem 1.

LEMma 5 (Period profits).

Given

$$
\begin{aligned}
\pi\left(G_{i t}, K_{i t}\right)= & S_{i t}\left(G_{i t}, K_{i t}, L_{i t}^{*}\left(G_{i t}, K_{i t}\right), M_{i t}^{*}\left(G_{i t}, K_{i t}\right)\right)-p_{L} L_{i t}^{*}\left(G_{i t}, K_{i t}\right) \\
& -p_{M} M_{i t}^{*}\left(G_{i t}, K_{i t}\right),
\end{aligned}
$$

then $\pi\left(\lambda G_{i t}, \lambda K_{i t}\right)=\lambda \pi\left(G_{i t}, K_{i t}\right)$.

Lemma 6 (Capital transition). $\quad \lambda K_{i t+1}\left(K_{i t}, I_{i t}\right)=K_{i t+1}\left(\lambda K_{i t}, \lambda I_{i t}\right)$.

Lemma 7 (Adjustment costs). $\lambda C_{i t}\left(G_{i t}, K_{i t}, I_{i t}\right)=C_{i t}\left(\lambda G_{i t}, \lambda K_{i t}, \lambda I_{i t}\right)$.

LEMma 8 (TFPR transition). Let process $B$ be written in terms of $g$ such that

$$
\begin{aligned}
(1-a-b-c) g_{i t+1}= & \mu_{i}+(1-\rho)(1-a-b-c) \log \lambda \\
& +\rho(1-a-b-c) g_{i t}+\sigma \epsilon_{i t}
\end{aligned}
$$

and let the associated distribution describing the transitions of $G$ be $\phi_{B}\left(G_{i t+1} \mid G_{i t}\right)$. Similarly, let $A$ be written as in equation (A2) and let the associated distribution describing the transitions of $G$ be $\phi_{A}\left(G_{i t+1} \mid G_{i t}\right)$. Then fixing $G_{i t}$ and $G_{i t+1}$,

$$
\phi_{B}\left(\lambda G_{i t+1} \mid \lambda G_{i t}\right)=\phi_{A}\left(G_{i t+1} \mid G_{i t}\right) .
$$

Proof. This follows from lemmas 1 and 2, noting that $\lambda^{1-a-b-c}=\Lambda$. QED

We now turn to the value function, as defined in equation (A4). Let $V_{A}(G, K)$ be the value function when the TFPR process is described by $A$. Similarly, let $V_{B}(G, K)$ be the value function when the TFPR process is described by $B$. That is,

$$
\begin{aligned}
V_{B}(G, K)= & \max _{I} \pi(G, K)-C(G, K, I) \\
& +\beta \int_{G^{\prime}} V_{B}\left(G^{\prime}, \delta K+I\right) \phi_{A}\left(d G^{\prime} \mid G\right) .
\end{aligned}
$$

Lemma 9 (Value function). For any $G$ and $K, V_{B}(\lambda G, \lambda K)=\lambda V_{A}(G, K)$.

Proof. We begin by defining $I_{A}^{*}(G, K)$ as the optimal investment policy corresponding to $V_{A}(G, K)$. We next define $W_{A}(G, K, I)$ as the choice-specific value function under process $A$. That is, $W_{A}(G, K, I)$ is the value generated when investment in the current period is set at $I$ rather than $I_{A}^{*}(G, K)$. So

$$
\begin{aligned}
W_{A}(G, K, I)= & \pi(G, K)-C(G, K, I) \\
& +\beta \int_{G^{\prime}} V_{A}\left(G^{\prime}, \delta K+I\right) \phi_{A}\left(d G^{\prime} \mid G\right) ;
\end{aligned}
$$

$W_{B}(G, K, I)$ is defined analogously. 
The proof proceeds by assuming that the future value function, $V_{B}\left(G^{\prime}, \delta K+I\right)$, satisfies the lemma and showing that this implies that $W_{B}(G, K, I)$ has the same property. We then show that this, in turn, implies that the present value function, $V_{B}(G, K)$, satisfies the lemma. Hence, in a stationary context, the proof exploits an inductive argument.

First, assume

$$
V_{B}\left(\lambda G^{\prime}, \lambda(\delta K+I)\right)=\lambda V_{A}\left(G^{\prime}, \delta K+I\right)
$$

Now

$$
\begin{aligned}
W_{B}(\lambda G, \lambda K, \lambda I)= & \pi(\lambda G, \lambda K)-C(\lambda G, \lambda K, \lambda I) \\
& +\beta \int_{\lambda G^{\prime}} V_{B}\left(\lambda G^{\prime}, \delta \lambda K+\lambda I\right) \phi_{B}\left(d \lambda G^{\prime} \mid \lambda G\right) .
\end{aligned}
$$

Next, from lemma 8 ,

$$
\begin{aligned}
W_{B}(\lambda G, \lambda K, \lambda I)= & \pi(\lambda G, \lambda K)-C(\lambda G, \lambda K, \lambda I) \\
& +\beta \int_{G^{\prime}} V_{B}\left(\lambda G^{\prime}, \delta \lambda K+\lambda I\right) \phi_{A}\left(d G^{\prime} \mid G\right) .
\end{aligned}
$$

Then from lemmas 5, 6, and 7 and the maintained assumption,

$$
\begin{aligned}
W_{B}(\lambda G, \lambda K, \lambda I)= & \lambda \pi(G, K)-\lambda C(G, K, I) \\
& +\lambda \beta \int_{G^{\prime}} V_{A}\left(G^{\prime},(\delta K+I)\right) \phi_{A}\left(d G^{\prime} \mid G\right) \\
= & \lambda W_{A}(G, K, I) .
\end{aligned}
$$

Next, we show that this implies that the present value function, $V_{B}(G, K)$, satisfies the lemma. First note that if $I_{A}^{*}(G, K)=\arg \max _{I} W_{A}(G, K, I)$, then $\lambda I_{A}^{*}(G, K)$ solves $\arg \max _{I} W_{B}(\lambda G, \lambda K, I)$ since $W_{B}(\lambda G, \lambda K, \lambda I)=\lambda W_{A}(G, K, I)$. Next,

$$
\begin{aligned}
V_{B}(\lambda G, \lambda K) & =\max _{I} W_{B}(\lambda G, \lambda K, I) \\
& =W_{B}\left(\lambda G, \lambda K, \lambda I_{A}^{*}(G, K)\right) \\
& =\lambda W_{A}\left(G, K, I^{*}(G, K)\right) \\
& =\lambda V_{A}(G, K) .
\end{aligned}
$$

Thus

$$
V_{B}(\lambda G, \lambda K)=\lambda V_{A}(G, K)
$$

QED

Lemma 10. Let $\left\{\epsilon_{i t}\right\}_{t=0}^{\infty}$ be a path of realizations of $\epsilon_{i t}$ and let $g_{i 0}$ and $K_{i 0}$ be the initial conditions of $g$ and $K$ under process $A$ and $g_{i 0}+\lambda$ and $\lambda K_{i 0}$ be the initial conditions under process $B$. Then, if $\left\{K_{i t}\right\}_{t=0}^{\infty}$ is the path of capital under process $A$, then $\left\{\lambda K_{i t}\right\}_{t=0}^{\infty}$ is the path under process $B$. 
Proof. This follows from lemmas 1, 8, and 9. As before, let $I^{*}(G, K)$ be the investment policy under process $A$. Now, consider the optimal investment problem under process $B$ with capital state $\lambda K$.

From lemma 9 we know that $\lambda I_{A}^{*}(G, K)=I_{B}^{*}(\lambda G, \lambda K)$. That is, if $I_{A}^{*}(G, K)$ is the solution when $\lambda=0$ (i.e., process $A$ ), then $\lambda I_{A}^{*}(G, K)$ is the solution when $\lambda>0$ (i.e., process $B$ ). Hence, under process $B$, the path of the capital stock is a level shift of that under process $A$. That is, if $\left\{K_{i t}\right\}_{t=0}^{\infty}$ is the path of capital under process $A$, then $\left\{\lambda K_{i t}\right\}_{t=0}^{\infty}$ is the path under process $B$. QED

Together, lemmas 3,4 , and 10 allow us to compare $\operatorname{SD}\left(s_{i t}-x_{i t}\right)$ and $\operatorname{SD}\left(x_{i t}-x_{i t-1}\right)$ under processes $A$ and $B$. With all else held constant, if $s_{i t}, x_{i t}$, and $x_{i t-1}$ are the realizations under $A$, then $s_{i t}+\log (\lambda), x_{i t}+\log (\lambda)$, and $x_{i t-1}+\log (\lambda)$ are the realizations under $B$. Since constants will be canceled out in the computing of differences, the theorem is established. QED

\section{Appendix B}

\section{Data}

We employ multiple data sets in our analysis. We classify these data sets into two tiers, shown in table 1 . Tier 1 consists of country-specific producer-level data from eight countries: the United States, Chile, France, India, Mexico, Romania, Slovenia, and Spain. Each of these data sets has been used extensively in the literature, most commonly in the analysis of productivity (see, e.g., Tybout and Westbrook 1995; Roberts 1996; Pavcnik 2002; Konings and Vandenbussche 2005; De Loecker and Konings 2006; De Loecker 2007; Goldberg et al. 2009; Bloom et al. 2011). Tier 2 consists of the World Bank Enterprise Survey (WBES). We discuss the details of each data set below. For a description of the measurement of productivity, see Section III.B.

\section{A. United States}

The data for the United States come from the US Census Bureau's Research Data Center Program. We use data on manufacturing plants from the Census of Manufactures (CMF) and the Annual Survey of Manufacturers (ASM) from 1972 to 1997. ${ }^{45}$ The CMF sends a questionnaire to all manufacturing plants in the United States with more than five employees every 5 years, while the ASM is a 4-year rotating panel with replacement, sent to approximately a third of manufacturing plants, with large plants being overrepresented in the sampling scheme.

Labor is measured using the total number of employees at the plant. Materials are measured using total cost of parts and raw materials.

Capital is constructed in two ways. For the majority of plants, including all plants in the CMF, capital is measured using a question on total assets-be they machines or buildings - at the plant. For the remaining observations, capital is constructed

${ }^{45}$ We use a version of these files that has been processed for productivity analysis by the staff at the Center for Economic Studies at the US Census Bureau, and more information on the construction of these data can be found in the productivity database files at the Census Bureau. 
using the perpetual inventory method, using industry-specific depreciation rates and investment deflators from the Bureau of Economic Analysis and the NBER. Capital, materials, and sales are deflated using the NBER-CES industry-level deflators into 1997 dollars.

The original data set has approximately 3 million plants. However, only 1.8 million of these have sufficient - that is, nonzero and nonmissing — data on sales, labor, capital, and materials, required to construct productivity. Out of these, we keep plantyears for which we have observations in consecutive years, which allow us to measure changes in productivity. There are several industries (measured by the four-digit SIC code) that have a small number of plants. We drop industries that have either (a) fewer than 50 plants in any given year or $(b)$ fewer than 1,000 plants over the entire sample period. The omission of these small-plant number industries has little effect on our estimates, and they represent a limited number of plants in the data; but dropping these small-plant number industries is essential for the disclosure of our results. The final data set has 735,342 plants over a 26 -year period.

\section{B. Chile}

Annual plant-level data on all manufacturing plants with at least 10 workers were provided by Chile's Instituto Nacional de Estadistica (INE). These data, which cover the period 1979-86, include production, employment, investment, intermediate input, and balance sheet variables. The data were prepared for analysis by INE: standardization of variable definitions across years, identification of entering and exiting plants and adjustment for inflation distortions, and construction of capital stock variables. Industries are classified according to the four-digit Industrial Standard Industrial Classification (ISIC) industry code.

Output and input price indices are constructed at the three-digit industry and obtained directly from average price indices produced by the Central Bank of Chile. Data on nominal and real values of the various capital goods are reported, including buildings, machinery, furniture, vehicles, and others and allow the construction of price deflators. We directly observe total number of employees, total real value of production, total real intermediate input, total real book value of fixed assets, and total real salaries. In total there are 37,600 plant-year observations reporting employment, with a minimum of 4,205 plants in 1983 and 5,814 plants in 1979 .

The data were generously provided by Jim Tybout through a license at the International Economics Section of Princeton University. See Pavcnik (2002) for a productivity study using these data.

\section{France, Romania, and Spain}

Annual firm-level data on manufacturing firms for France, Romania, and Spain are obtained from Bureau Van Dijck's (BvD) Amadeus data set and cover firms reporting to the local tax authorities or data collection agencies for the period 1999-2007. We selected three relatively large European countries at different stages of economic development. The coverage for all three countries is sub- 
stantial in that we cover approximately 90 percent of economic activity in each of the three manufacturing sectors. For example, for France, in 2000, we record total sales of $€ 739$ billion, whereas the OECD reports total sales to be $€ 768$ billion. This implies coverage of 96 percent of total economic activity in manufacturing. For Spain we find, using the same coverage calculation, coverage of 88 percent. The collection protocol of $\mathrm{BvD}$ is consistent across countries. We focus on the manufacturing sector to facilitate the measurement of productivity.

The data include standard production data, where we observe total operating revenue (production); total number of employees (employment); total material costs (intermediate input); total costs of employees (wage bill); total fixed assets and all the subcomponents of the capital stock such as buildings, furniture, vehicles, equipment, and others; as well as other standard income statement and balance sheet variables. The data also provide information on the firm's legal status, whether the firm is active, and its consolidation code. We use this information to make sure that we include only firms actively producing in a specific industry and use only their unconsolidated accounts to, for instance, avoid including total sales of a multinational across affiliates located in different countries. These data are known to slightly underrepresent small firms because of the threshold on either firm size or total number of employees (see Bloom et al. [2011] and Larrain and Stumpner [2012] for more discussion). ${ }^{46}$

Industries are classified according to the two-digit NACE revision 1.1 code for all three countries. Our data cover firms primarily active in sectors NACE 15-36.

The manufacturing sector in each country leaves us with 391,422, 174,435, and 457,934 firm-year observations for France, Romania, and Spain. Two-digit NACE industry producer prices are used to deflate all nominal values and are downloaded from EUROSTAT's online statistics database. ${ }^{47}$

Access to BvD's Amadeus was obtained through Princeton University's Library license. For recent work drawing on the Amadeus data, see Bloom et al. (2011) and the discussion therein.

\section{India}

Annual firm-level data on manufacturing firms were provided by Prowess and are collected by the Centre for Monitoring the Indian Economy. Prowess is a panel that tracks firm performance over time. These data cover the period 1989-2003 and contain mainly medium and large Indian firms.

Industries are classified according to the PNIC classification code (India's industrial classification system), and firms report the principal industry activity at the four-digit PNIC level.

These data include various production, employment, investment, intermediate input, and balance sheet variables. In particular, we observe total sales, total material costs, total fixed assets, and total wage bill. The data report both product-

${ }^{46}$ In table D.5 in the online appendix, we verify that our results are invariant to imposing a common threshold across all our data sets.

${ }^{47}$ See http://appsso.eurostat.ec.europa.eu/nui/setupModifyTableLayout.do. The data are found under "Industry, trade and services $>$ Short-term business statistics $>$ Producer prices in industry." 
level sales and total sales. We aggregate product-level sales to the firm level. The Indian data do not report the wage bill separate from the number of workers. We do, however, take care to appropriately deflate the wage bill. All nominal values are converted to real values using two-digit producer prices. In total there are 30,709 firm-year observations reporting a wage bill, and there are 4,154 firms active throughout the sample period.

The data are used in Goldberg et al. (2009) and were bought under a license by Goldberg, Khandelwal, and Pavcnik. For recent work using the same data in the context of production function estimation, see De Loecker et al. (2012); more details on the data are discussed therein.

\section{E. Mexico}

Annual plant-level data on manufacturing plants are recorded by Mexico's Annual Industrial Survey and are provided by Mexico's Secretary of Commerce and Industrial Development (SEC-OFI). The sample of plants (the 3,200 largest manufacturing firms) represents approximately 8 percent of total output, where the excluded plants are the smallest ones. For each plant and year, we observe the usual data on production, input use, investment, inventories, and costs, as well as industry codes and plant identity codes that allow us to track establishments over time.

Industries are classified according to the Mexican Industrial Classification (a four-digit industrial classification system).

These data, which cover the period 1984-90, include production, employment, investment, intermediate input, and balance sheet variables. In particular, we use total value of output, total employment, total material costs, and total fixed assets. SEC-OFI also provided price indices at the industry level for output and intermediate inputs and sectorwide deflators for machinery and equipment, buildings, and land, which we used to convert all nominal values to real values. In total there are 21,180 plant-year observations reporting employment, with a minimum of 2,958 plants in 1989 and 3,175 plants in 1984 .

The data were generously provided by Jim Tybout through a license at the International Economics Section at Princeton University. Tybout and Westbrook (1995) contains more details and contains an application to productivity analysis.

\section{F. Slovenia}

The data are taken from the Slovenian Central Statistical Office and are the full company accounts of all firms operating in the manufacturing sector between 1994 and 2000. The original accounting data for the period between 1994 and 2002 were provided by Agency of the Republic of Slovenia for Public Legal Records and Related Services.

We have information on 7,915 firms: an unbalanced panel with information on production, employment, investment, intermediate input, and balance sheet variables. In particular, we observe total sales, total material costs, total fixed assets, total cost of employees, and total number of employees. All monetary variables are recorded in Slovenian tolars and have been deflated using the consumer price index (for data relating to capital stock) and a producer price index 
(at the two-digit NACE industry level). In total there are 29,058 firm-year observations reporting employment, with a minimum of 3,355 in 1994 and a maximum of 4,788 firms in 2000. The sharp increase in the number of firms, in contrast to data sets with thresholds on firm size, reflects the sharp growth of Slovenia and the manufacturing sector in particular. See, for example, De Loecker and Konings (2006) for a discussion on the entry of de novo firms during the transition period - which is covered in our sample period.

Industries are classified according to the two-digit NACE code for all three countries. Our data cover firms primarily active in sectors NACE 15-36.

We would like to thank Joze Damijan at Ljublijana University for sharing the data. We refer the reader to De Loecker and Konings (2006) and De Loecker (2007) for more on the data and an application to production function estimation.

\section{G. World Bank Data}

The World Bank Enterprise Survey (WBES) data were collected by the World Bank across 41 countries and many different industries between 2002 and 2006. Standard output and input measures are reported in a harmonized fashion. In particular, we observe sales, intermediate inputs, various measures of capital, and employment during (and covering up to) a 3-year period, which allows us to compute changes in TFPR and capital. Out of the 41 countries in the data, 33 have usable firm-level observations. The reason is primarily that, for many years and countries, the World Bank did not collect multiyear data on capital stock. Table B1 lists the countries we are able to use, together with the number of observations on each country. The data are available from http://www.enterprisesurveys.org, accessed on December 15, 2010. Extensive documentation is available from the same website.

The survey documentation describes the sampling universe as follows: " 6 . The population of industries to be included in the Enterprise Surveys and Indicator Surveys, the Universe of the study, includes the following list (according to ISIC, revision 3.1): all manufacturing sectors (group D), construction (group F), services (groups $\mathrm{G}$ and $\mathrm{H}$ ), transport, storage, and communications (group I), and subsector 72 (from Group K). Also, to limit the surveys to the formal economy the sample frame for each country should include only establishments with five (5) or more employees. Fully government owned establishments are excluded as the Universe is defined as the non-agricultural private sector." 48

The survey used a stratified sampling procedure in which firms were sampled randomly within groups on the basis of the firm's sector of activity, firm size, and geographical location. The structure of the sampling leads to an oversampling of larger firms (relative to random sampling of all firms in the economy). The exact structure of the stratification varies by the size of the economy in question. We have chosen not to do any sampling correction, preferring to maintain as much transparency as possible as to the mapping from data to findings, being mindful of the fact that we can use data from only 7 percent of the sampled firms in any case and, most importantly, considering the absence of a well-defined criterion

48 "Enterprise Survey and Indicator Surveys Sampling Methodology" (August 29, 2009, 3) at http://www.enterprisesurveys.org/Documents/Sampling_Note.pdf. 
TABLE B1

Countries in the World Bank Data Sample

\begin{tabular}{|c|c|c|}
\hline Region and Country & SD(MRPK) & Firms \\
\hline \multicolumn{3}{|l|}{ North Africa: } \\
\hline Morocco & .75 & 376 \\
\hline \multicolumn{3}{|l|}{ Sub-Saharan Africa: } \\
\hline Benin & .81 & 66 \\
\hline Ethiopia & 1.31 & 211 \\
\hline Madagascar & .93 & 84 \\
\hline Malawi & 1.03 & 125 \\
\hline Mauritius & 1.49 & 52 \\
\hline South Africa & 1.29 & 199 \\
\hline Tanzania & 1.65 & 58 \\
\hline Zambia & .82 & 157 \\
\hline \multicolumn{3}{|l|}{ Central Asia: } \\
\hline Kyrgyzstan & .53 & 94 \\
\hline Tajikistan & .87 & 94 \\
\hline Uzbekistan & .89 & 92 \\
\hline \multicolumn{3}{|l|}{ Middle East: } \\
\hline Syria & 1.13 & 55 \\
\hline \multicolumn{3}{|l|}{ South Asia: } \\
\hline Bangladesh & 1.28 & 134 \\
\hline Sri Lanka & .96 & 114 \\
\hline \multicolumn{3}{|l|}{ Southeast Asia: } \\
\hline Indonesia & 1.53 & 426 \\
\hline Philippines & 1.06 & 278 \\
\hline Thailand & .75 & 214 \\
\hline Vietnam & .95 & 448 \\
\hline \multicolumn{3}{|l|}{ Central America: } \\
\hline Costa Rica & 1.22 & 273 \\
\hline Ecuador & 1.51 & 109 \\
\hline El Salvador & .95 & 190 \\
\hline Guatemala & .95 & 162 \\
\hline Honduras & 1.10 & 203 \\
\hline Nicaragua & 1.14 & 222 \\
\hline \multicolumn{3}{|l|}{ South America: } \\
\hline Brazil & 1.00 & 85 \\
\hline Chile & 1.40 & 745 \\
\hline Guyana & 2.37 & 29 \\
\hline Peru & .85 & 31 \\
\hline \multicolumn{3}{|l|}{ Europe: } \\
\hline Moldova & .94 & 72 \\
\hline Lithuania & 1.37 & 66 \\
\hline Poland & .58 & 63 \\
\hline Turkey & 1.87 & 36 \\
\hline
\end{tabular}

that could be used to guide any such correction. In any case, the results in the paper are robust to controlling for differences in the size and industrial composition of firms across countries.

The firms in the data are drawn from the manufacturing, construction, services, transport, storage, and communications sectors. As would be expected, the precise industry composition (defined at the two-digit ISIC level) varies by country. The majority of firms within a country were surveyed in the same year. The 
survey asked questions about activity in the current year and the previous 2 years. Thus, the panel data aspect of these data, relating to activity in year $t-1$, comes from the recollections and records of managers in year $t$.

To construct data on TFPR and the change in TFPR, we need two years of information on sales, assets, intermediate inputs, and employment; 5,558 firms across our 33 countries meet this criterion. ${ }^{49}$ For some of the countries in the WBES data, a number of issues emerged in the calculation of TFPR. In particular, labor use is typically reported as the number of employees or a wage bill converted to the number of employees with no correction for hours worked. Moreover, sales and gross output data are not corrected for inventories, and the capital stock is based on book values. These are standard data restrictions researchers face using this type of data.

Sales are directly measured in the data. Hence, for many firm-years in the data, we can compute TFPR directly. However, for some firm-years, we observe only the firm's wage bill and not the number of workers. To address this issue, we use the median country-industry wage, $\tilde{w}$ (imputed from observations with both the wage bill and the number of workers), as a deflator and apply it to the wage bill to give a measure of labor. That is, to compute $L_{i t}$ we use $L_{i t}=w L_{i t} / \tilde{w}$. In what is presented in this paper, we use this measure for all firm-year observations. Finally, we rely on the book value of capital as measured by either total assets or net book value. We experimented with both measures, and our results are invariant. When we consider a measure of value added, we compute it by netting the sales variable from the use of intermediate inputs.

Finally, we convert all relevant variables into real values using detailed producer price and input price deflators where available. For the 33 countries covered in the World Bank data, we rely on the World Bank deflators to convert all monetary variables into US dollars. To do this, we use the World Bank's measure of purchasing power parity (PA.NUS.PPP). Note that we account for differences in the rate of inflation across countries by using a year-specific measure of PPP. Since TFPR is a ratio, these PPP conversions get netted out in many specifications, but they are useful when, for instance, we use controls for firm size.

While there are over 41,000 observations in the data, only 5,558 have information on capital over several years, which is needed to compute TFPR volatility. Table B2 presents summary statistics of the data, where for each variable, the first line refers to the data that we use and the second presents the data that we dropped because of insufficient information to compute changes in TFPR. ${ }^{50}$ The dropped observations are usually smaller firms with lower sales and fewer employees. However, changes in inputs (such as changes in capital or labor) are comparable across the data we did and did not use. Notice that the dispersion of TFPR is similar between the two data sets, with a standard deviation of 1.0 (our data) versus 1.2 (dropped data), as well as the dispersion of the sales to capital ratio, which is 1.1 (our data) versus 1.3 (dropped data). Thus, the sampling bias will slightly under-

${ }^{49}$ We also drop countries with fewer than 25 observations. This has little effect on our results. See table D. 6 for the results based on the entire sample, i.e., for 36 countries instead of 33 . The results are virtually identical.

${ }^{50}$ Summary statistics, analogous to table 2, can be found in table D.1 in the online appendix. 
TABLE B2

Selection Bias Due to Missing Data in World Bank Data

\begin{tabular}{lccc}
\hline \hline & & Standard & \\
Variable & Mean & Deviation & Observations \\
\hline Log sales & 7.0 & 3.1 & 5,579 \\
& 6.7 & 3.3 & 51,043 \\
Log value added & 6.0 & 3.1 & 4,719 \\
& 5.9 & 3.3 & 42,230 \\
Log materials & 6.4 & 3.3 & 5,579 \\
& 5.2 & 3.5 & 46,642 \\
Log capital & 6.9 & 3.1 & 5,579 \\
Log labor & 7.5 & 3.0 & 12,728 \\
& 5.2 & 2.9 & 4,715 \\
Workers & 4.8 & 3.1 & 23,696 \\
& 284 & 874 & 5,579 \\
Productivity & 145 & 1,010 & 50,891 \\
& 2.3 & 1.0 & 5,579 \\
Sales to capital ratio & 2.4 & 1.2 & 4,750 \\
Sales to labor ratio & .1 & 1.1 & 5,579 \\
& .2 & 1.3 & 12,528 \\
Change in capital & 2.9 & 2.2 & 5,579 \\
& 3.1 & 3.2 & 37,918 \\
Change in labor & .1 & .5 & 5,579 \\
& .1 & .5 & 11,268 \\
Change in the sales to capital ratio & .2 & .7 & 4,626 \\
& .0 & .6 & 14,360 \\
& .0 & .7 & 5,579 \\
\end{tabular}

Note.-The first row shows the data used in the paper, and the second row indicates data that we dropped because of some missing observation.

state the level of TFPR and MRPK dispersion, but this effect is small relative to the large differences in dispersion across countries.

\section{Appendix C}

\section{Model Computation}

The parameters we use are found in table C1. Parameters for the elasticity of demand, depreciation rate, and discount rate follow those adopted by Bloom (2009). The last set of parameters we need to fix are the $\sigma, \rho$, and $\mu$ terms in the $\mathrm{AR}(1)$ process, which governs the evolution of productivity over time. We compute the model for values of $\sigma$ between 0.1 and 1.4, which covers the range we observe in the data. For $\rho$ we pick three values, $0.65,0.85$, and 0.94 . Finally, we set $\mu=0$. We also implicitly normalize the prices of noncapital inputs by setting $\lambda$ $=1$. More precisely, what we are normalizing is $\lambda$, a function of these noncapital input prices. The functional form of $\lambda$ puts structure on the relative prices of noncapital inputs. Subject to this structure, normalizing $\lambda$ is equivalent to a normalization of one of the noncapital input prices. 
TABLE C1

Simulation Parameters

\begin{tabular}{ll}
\hline \hline Parameter & \\
\hline$\epsilon=-4$ & Value also used in Bloom $(2009)$ \\
$\delta=10 \%$ & Value also used in Bloom $(2009)$ \\
$\beta=1 /(1+6.5 \%)$ & Value also used in Bloom $(2009)$ \\
$\beta_{K}=0.12$ & Mean value in US census data \\
$\beta_{M}=0.40$ & Mean value in US census data \\
$\beta_{L}=0.23$ & Mean value in US census data \\
$C_{K}^{F}=0.09$ & Estimated using US census data; see Sec. V.A \\
$C_{K}^{Q}=8.8$ & Estimated using US census data; see Sec. V.A \\
$\rho \in\{0.65,0.85,0.94\}$ & Selected to fall within range of estimated values for the US census \\
$\sigma \in[0.1,1.4]$ & Selected to fall within range of estimated values for the US census \\
$\lambda=1$ & Scaling parameter that normalizes the price of noncapital inputs \\
$\mu=0$ & Normalization that has no effect on computed moments, by \\
& theorem 1 \\
\hline
\end{tabular}

We compute the optimal investment policies for the value function in equation (9). We solve this model using a discretized version of the state space $\left(\Omega_{i t}, K_{i t}\right)$. Specifically, we use a grid of capital states ranging from log capital 3 to log capital equal to 20, in increments of 0.03 . Moreover, we use a grid of productivity with 30 grid points, whose transition matrix and grid points are computed using Tauchen's (1986) method. The model is solved using policy iteration with a sparse transition matrix (since there are 17,000 states). Using the computed optimal policies, we simulate the evolution of a country, or industry, for 10,000 firms over 1,000 periods. We use the output from the 1,000 th and 988 th periods to compute the reported results (corresponding to years $t$ and $t-1$; recall that we interpret a period as a month).

\section{References}

Bachmann, Rudiger, and Giuseppe Moscarini. 2012. "Business Cycles and Endogenous Uncertainty." Technical report, Yale Univ.

Bartelsman, E. J., and M. Doms. 2000. "Understanding Productivity: Lessons from Longitudinal Microdata." J. Econ. Literature 38 (3): 569-94.

Bartelsman, E. J., J. C. Haltiwanger, and S. Scarpetta. 2013. "Cross-Country Differences in Productivity: The Role of Allocation and Selection.” A.E.R. 103 (1): 305-34.

Bloom, Nicholas. 2009. "The Impact of Uncertainty Shocks.” Econometrica 77 (3): 623-85.

Bloom, Nicholas, Mirko Draca, and John Van Reenen. 2011. "Trade Induced Technical Change? The Impact of Chinese Imports on Innovation, IT and Productivity." Technical report, NBER, Cambridge, MA.

Bloom, Nicholas, B. Eifert, A. Mahajan, D. McKenzie, and J. Roberts. 2013. "Does Management Matter? Evidence from India.” Q.J.E. 128 (1): 1-51.

Bloom, Nicholas, Max Floetotto, Nir Jaimovich, Itay Saporta-Eksten, and Stephen J. Terry. 2012. "Really Uncertain Business Cycles." Working Paper no. 18245, NBER, Cambridge, MA. 
Bollard, Albert, Peter J. Klenow, and Gunjan Sharma. 2012. “India's Mysterious Manufacturing Miracle." Rev. Econ. Dynamics 16 (1): 59-85.

Caballero, Ricardo J., and Richard S. Pindyck. 1993. "Uncertainty, Investment, and Industry Evolution." Internat. Econ. Rev. 37 (3): 641-62.

- 1996. "Uncertainty, Investment, and Industry Evolution." Internat. Econ. Rev. 37 (3): 641-62.

Collard-Wexler, Allan. 2009. "Productivity Dispersion and Plant Selection in the Ready-Mix Concrete Industry." Working paper, New York Univ.

_. 2013. "Demand Fluctuations in the Ready-Mix Concrete Industry." Econometrica 81 (3): 1003-37.

Collard-Wexler, Allan, and Jan De Loecker. Forthcoming. "Reallocation and Technology: Evidence from the U.S. Steel Industry." A.E.R.

Cooper, R. W., and J. C. Haltiwanger. 2006. "On the Nature of Capital Adjustment Costs." Rev. Econ. Studies 73 (3): 611-33.

De Loecker, Jan. 2007. "Do Exports Generate Higher Productivity? Evidence from Slovenia." J. Internat. Econ. 73 (1): 69-98.

De Loecker, Jan, P. Goldberg, A. Khandelwal, and N. Pavcnik. 2012. "Prices, Markups and Trade Reform." Working paper, NBER, Cambridge, MA.

De Loecker, Jan, and J. Konings. 2006. "Job Reallocation and Productivity Growth in an Emerging Economy: Evidence from Slovenian Manufacturing." European J. Polit. Econ. 22:388-408.

De Loecker, Jan, and F. Warzynski. 2012. "Markups and Firm-Level Export Status." A.E.R. 102 (6): 2437-71.

De Mel, S., D. McKenzie, and C. Woodruff. 2012. "Enterprise Recovery Following Natural Disasters.” Econ. J. 122 (559): 64-91.

Dixit, Avinash K., and Robert S. Pindyck. 1994. Investment under Uncertainty. Princeton, NJ: Princeton Univ. Press.

Fisher-Vanden, K., E. T. Mansur, and Q. J. Wang. 2012. "Costly Blackouts? Measuring Productivity and Environmental Effects of Electricity Shortages." Technical report, NBER, Cambridge, MA.

Fisman, R., and J. Svensson. 2007. "Are Corruption and Taxation Really Harmful to Growth? Firm Level Evidence.” J. Development Econ. 83 (1): 63-75.

Foster, L., J. Haltiwanger, and C. Syverson. 2008. "Reallocation, Firm Turnover, and Efficiency: Selection on Productivity or Profitability?” A.E.R. 98 (1): 394-425.

Goldberg, P., A. Khandelwal, N. Pavcnik, and P. Topalova. 2009. "Trade Liberalization and New Imported Inputs." A.E.R. 99 (2): 494-500.

Hamilton, James. 1994. Time Series Analysis. Princeton, NJ: Princeton Univ. Press.

Hsieh, Chang-Tai, and Peter J. Klenow. 2009. "Misallocation and Manufacturing TFP in China and India." Q.J.E. 124 (4): 1403-48.

Kehrig, Matthias. 2011. "The Cyclicality of Productivity Dispersion." Center for Economic Studies Paper no. CES-WP-11-15, US Census Bur., Washington, DC.

Konings, Jozef, and Hylke Vandenbussche. 2005. "Antidumping Protection and Markups of Domestic Firms." J. Internat. Econ. 65 (1): 151-65.

Larrain, Mauricio, and Sebastian Stumpner. 2012. "Understanding Misallocation: The Importance of Financial Constraints.” Technical report, Columbia Univ.

Lucas, Robert E., Jr. 1967. "Adjustment Costs and the Theory of Supply.” J.P.E. 75, no. 4, pt. 1 (August): 321-34.

Midrigan, Virgiliu, and Daniel Yi Xu. 2014. "Finance and Misallocation: Evidence from Plant-Level Data." A.E.R. 104 (2): 422-58.

Moll, Benjamin. 2012. "Productivity Losses from Financial Frictions: Can SelfFinancing Undo Capital Misallocation?” Technical report, Princeton Univ. 
Olley, G. Steven, and Ariel Pakes. 1996. "The Dynamics of Productivity in the Telecommunications Equipment Industry.” Econometrica 64 (6): 1263-97.

Pakes, Ariel. 1996. "Dynamic Structural Models, Problems and Prospects: Mixed Continuous Discrete Controls and Market Interaction." In Advances in Econometrics: Sixth World Congress, vol. 2, edited by Christopher Sims, 171-259. New York: Cambridge Univ. Press.

Pavcnik, Nina. 2002. "Trade Liberalization, Exit, and Productivity Improvements: Evidence from Chilean Plants." Rev. Econ. Studies 69 (1): 245-76.

Peters, Michael. 2012. "Heterogeneous Mark-ups and Endogenous Misallocation." Technical report, London School Econ.

Restuccia, Diego, and Richard Rogerson. 2008. "Policy Distortions and Aggregate Productivity with Heterogeneous Establishments." Rev. Econ. Dynamics 11 (4): 707-20.

Roberts, M. J. 1996. "Colombia, 1977-1985: Producer Turnover, Margins, and Trade Exposure." In Industrial Evolution in Developing Countries: Micro Patterns of Turnover, Productivity and Market Structure, edited by M. J. Roberts and J. Tybout, 227-59. New York: Oxford Univ. Press.

Syverson, Chad. 2011. "What Determines Productivity." J. Econ. Literature 49 (2): $326-65$.

Tauchen, G. 1986. "Finite State Markov-Chain Approximations to Univariate and Vector Autoregressions.” Econ. Letters 20 (2): 177-81.

Tybout, J. R., and M. D. Westbrook. 1995. "Trade Liberalization and the Dimensions of Efficiency Change in Mexican Manufacturing Industries." J. Internat. Econ. 39 (1): 53-78. 